\title{
Proto-Jabutí: um primeiro passo na reconstrução da língua ancestral dos Arikapú e Djeoromitxí
}

Proto-Jabutí: a first attempt to reconstruct the ancestral language of the Arikapú and the Djeoromitxí

Resumo: As línguas Arikapú e Djeoromitxí constituem uma pequena família lingüística no sul de Rondônia chamada Jabutí. Estão altamente ameaçadas de extinção e apenas recentemente dados de alta qualidade tornaram-se disponíveis. Este artigo pretende criar uma base de evidência para a hipótese de Curt Nimuendajú de que a família lingüística Jabutí pertence ao tronco lingüístico Macro-jê. Após apresentar esboços breves de ambas as línguas Jabutí e do contexto histórico e sociocultural, o artigo concentra-se na reconstrução da língua ancestral, Proto-Jabutí, seguindo os princípios do método histórico-comparativo.

Palavras-chave: Línguas indígenas. Família Jabutí. Reconstrução histórica. Fonologia. Morfossintaxe. Tronco Macro-Jê.

Abstract: The Arikapú and Djeoromitxí languages form a small linguistic family in southern Rondônia, known as Jabutí. The languages are highly endangered and high quality data have become available only recently. This article is intended to create a basis of evidence for Curt Nimuendajú's hypothesis that the Jabutí language family belongs to the Macro-jê linguistic stock. After short descriptive sketches of both Jabutí languages and the historical and sociocultural background, the article focusses on the reconstruction of the ancestral language, Proto-Jabutí, following the principles of the historical-comparative method.

Keywords: Indigenous languages. Jabutí family. Historical reconstruction. Phonology. Morphosyntax. Macro-Jê stock.

\footnotetext{
Museu Paraense Emílio Goeldi. Radboud Universiteit Nijmegen. Departamento de Lingüística. Países Baixos (hvoort@xs4all.nl).
}

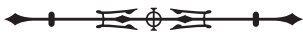




\section{INTRODUÇÃO}

Os povos Jabutí são constituídos por duas tribos indígenas que tradicionalmente habitavam o sul de Rondônia: os Arikapú e os Djeoromitxí. Os primeiros contatos entre estes povos e os não indígenas provavelmente ocorreram no início do século XX. De acordo com sua própria história oral, os Jabutí habitavam as cabeceiras do rio Branco e, como a maioria dos grupos do sul de Rondônia, eram provavelmente compostos por alguns milhares de indivíduos. Após contato com os não indígenas, os dois povos foram dizimados e deslocados. Atualmente, a maioria dos Jabutí restantes habita a Terra Indígena (T. I.) Rio Branco e a T. I. Rio Guaporé. As línguas dos Arikapú e Djeoromitxí são estreitamente ligadas e formam uma família lingüística pequena, chamada Jabutí. Provavelmente esta família não é isolada, mas constitui um ramo do tronco lingüístico Macro-Jê. Para realmente comprovar a inclusão de uma família lingüística em um tronco, primeiro é útil reconstruir a proto-língua da família em questão. O presente artigo trata de Proto-Jabutí, a língua falada pelos ancestrais dos Arikapú e Djeoromitxí, no tempo em que estas tribos ainda não tinham se separado. A conexão entre Jabutí e Macro-Jê é discutida em um outro artigo (Ribeiro; van der Voort, no prelo).

\section{OS POVOS}

Nesta seção, será resumido o contexto histórico e social das tribos Jabutí. Para uma exposição mais abrangente, veja van der Voort (2006).

\section{NOMES TRIBAIS}

As autodenominações dos dois povos Jabutí são Arikapú e Djeoromitxí. Estas são também as denominações utilizadas por cada grupo para se referir ao outro.

Jabutí é o nome popular criado e usado por não indígenas para referir aos Djeoromitxí. Além disso, a palavra Jabutí, ou Yabuti, é encontrada em algumas fontes lingüísticas para se referir à família lingüística que inclui as línguas Arikapú e Djeoromitxí (por exemplo, Greenberg, 1987). Em face à utilidade de uma única denominação para identificar os dois grupos étnicos e suas línguas, talvez seja útil reservar a denominação Jabutí para os primeiros. É assim que faço neste artigo.

Outro nome encontrado na literatura é Maxubí ou Mashubi, que faz referência a um grupo étnico que provavelmente falava Arikapú (Caspar, 1955). Este nome foi registrado uma única vez pela expedição do coronel inglês Percy Fawcett, em 1914 (Fawcett, 1953). O nome não é reconhecido por nenhum grupo étnico atual da região e sua etimologia é desconhecida.

Existem ainda outros nomes para as tribos Jabutí, como Burukayo, Kurupu, e outros (veja van der Voort, 2006), mas estes são menos conhecidos e não está claro se referem-se a subgrupos ou a clãs desaparecidos de falantes da mesma língua, ou a tribos extintas falantes de línguas relacionadas ou completamente diferentes.

\section{CONTEXTO TRADICIONAL}

Não é conhecida a origem dos povos Jabutí e suas próprias tradições orais não contêm informações que indiquem um tempo anterior à sua chegada na região do Guaporé. Por outro lado, as relações lingüísticas estreitas entre Arikapú e Djeoromitxí, em combinação com a adjacência geográfica dos dois povos, sugerem que os povos Jabutí chegaram em Rondônia antes da sua diversificação. $\bigcirc$ habitat tradicional desses povos é a floresta tropical úmida. Segundo seus 
próprios relatos, sempre viveram nas cabeceiras do rio Branco. Suas línguas não contêm palavras para os peixes que habitam o baixo rio e o Guaporé, tais como o surubim (gênero Platystomatichthys).

Segundo Caspar (1975), até 1955, habitavam a margem esquerda e os afluentes esquerdos do rio Branco, acima do local da atual cidade de Alta Floresta d'Oeste. Os Djeoromitxí viviam rio abaixo dos Arikapú. Seus vizinhos tradicionais eram os Makuráp e Wayurú, da família lingüística Tuparí (tronco Tupí), que viviam rio abaixo, na margem esquerda do rio Branco e na cabeceira do rio Colorado, respectivamente (ver também Maldi, 1991, p. 238-243). Na margem direita viviam os Tuparí, inimigos dos Jabutí. Mais para baixo ainda viviam os Aruá, da família lingüística Mondé (tronco Tupí).

Antes do contato com não indígenas, talvez os povos Jabutí chegassem a alguns milhares de indivíduos cada. Ocupavam grandes malocas em forma de colméia e sua subsistência se baseava na pesca, caça, coleta de frutas e insetos e agricultura de roçado. Plantavam milho, macaxeira (não plantavam mandioca brava), amendoim, inhame, banana, cabaça e criavam larvas comestíveis de várias espécies de insetos. Em termos culturais, os povos Jabutí eram estreitamente ligados aos outros grupos étnicos do sudoeste de Rondônia, com os quais compartilhavam algumas características específicas, tais como o uso de rapé (ou paricá) pelos pajés, um pó alucinógeno à base de sementes de angico (Anadenanthera peregrina), para se comunicarem com os espíritos. O marico, uma bolsa de crochê, feita à mão pelas mulheres, de fios tecidos de fibra de folhas de tucumã ou de buriti, também caracteriza os povos do sul de Rondônia. A etnohistoriadora Denise Maldi (1991) define o 'complexo cultural Marico' por estas características. A região cultural inclui vários grupos do tronco Tupí, os dois grupos Jabutí, bem como os Kanoê, Aikanã e Kwazá, que falam línguas isoladas e não pertencem a nenhuma família lingüística conhecida. Denise Maldi (1991) e a antropóloga Betty Mindlin registraram histórias tradicionais dos povos Jabutí (Mindlin et al., 1998, 1999).

\section{CONTEXTO ATUAL}

Os últimos representantes da geração nascida nos tempos tradicionais se recordam que viviam nas cabeceiras do rio Branco. Após o contato com os não indígenas, as sociedades indígenas do sul de Rondônia sofreram desintegração e deslocamento de seus membros. Por volta de 1920, muitos Jabutí desceram o rio para trabalhar no seringal de Paulo Saldanha, onde muitos Tuparí também chegaram em 1927. Entre 1930 e 1960, as pessoas eram obrigadas a descer mais ainda, até o seringal de São Luis, onde se concentravam também muitos Makuráp, Aruá e Wayurú. Nesta época muitas pessoas também foram encaminhadas à colônia Ricardo Franco, no rio Guaporé. Adicionalmente, muitas outras livraram-se do aviamento fugindo para Guajará-Mirím, naquela época a capital do Território, de onde foram transferidas para Ricardo Franco ou a outras reservas no vale do Guaporé. Atualmente, os Jabutí restantes vivem principalmente na T. I. Rio Branco e na T. I. Rio Guaporé. Nos locais mais isolados destas reservas, as línguas indígenas e os aspectos das culturas tradicionais continuam preservados.

Apesar de morarem em áreas protegidas em terras públicas federais, os habitantes da T.I. Rio Branco e da T.I. Rio Guaporé são ameaçados pelo modelo político e econômico de desenvolvimento predatório em diversas maneiras. Há desmatamento contínuo ao redor e invasores entram na reserva praticando ilegalmente a pesca comercial e dragagem de cascalho. Além disso, pesticidas empregados nas fazendas fora da reserva prejudicam o rio e a saúde dos índios. Os projetos hidrelétricos irregulares da região também provocam danos graves aos ecossistemas fluviais e ameaçam os sítios arqueológicos.

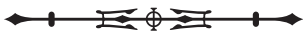




\section{AS LÍNGUAS}

Nesta seção, serão resumidos o contexto sociolingüístico das línguas Jabutí e a história do seu estudo. Subseqüentemente, serão discutidas as características básicas das duas línguas Jabutí.

\section{SITUAÇÃO SOCIOLINGÜÍSTICA E O ESTUDO DAS LÍNGUAS JABUTÍ}

Até recentemente, as línguas nativas dos Arikapú e dos Djeoromitxí permaneciam praticamente não-documentadas. Apesar disso, com base nas resumidas listas de palavras existentes, eram consideradas, desde a década de 1930, como constituindo a família lingüística Jabutí. Algumas fontes lingüísticas também fazem referência a uma suposta terceira língua Jabutí, hoje extinta, chamada Maxubí. Todavia, a lista de palavras coletadas junto aos Maxubí em 1914 por Percy Fawcett (Rivet, 1953) sugere que a língua seria bastante semelhante a Arikapú, o que foi observado pela primeira vez por Franz Caspar (1955). Esta lista de palavras representa a primeira documentação de uma língua Jabutí. Vinte anos mais tarde, o etnógrafo alemão Emil Heinrich Snethlage visitou a região do Guaporé, a serviço do Museu de Etnologia de Berlim, e gravou listas de palavras Arikapú e Djeoromitxí (que ele chamou de Kipiu) (Snethlage, 1937, 1939). Entre 1948 e 1955, o etnógrafo suíço Franz Caspar trabalhou na região do rio Branco, ficando conhecido pelo seu trabalho impressionante sobre a cultura tradicional Tuparí (Caspar, 1958, 1975). Caspar também compilou listas extensas de palavras Djeoromitxí e Arikapú. Em 1968, os lingüistas missionários Willem Bontkes e Robert Campbell, do Summer Institute of Linguistics, compilaram pequenas listas de palavras Arikapú e Djeoromitxí. No final da década de 1980, o lingüista Denny Moore, do Museu Paraense Emílio Goeldi, compilou listas comparativas de palavras das línguas Jabutí (Moore, 1988). Posteriormente, a lingüista Nádia Pires fez pesquisa de campo para uma tese de mestrado sobre a gramática da língua Djeoromitxí (Pires, 1992) e produziu material de alfabetização nesta língua (Pires et al., 1994, 1995). Entre 2001 e 2004, eu mesmo fiz pesquisa de campo com os últimos dois falantes de Arikapú.

O total de pessoas falando Djeoromitxí atualmente encontra-se reduzido a menos de 50 e o de Arikapú, no limiar da extinção, restando somente dois anciãos que falam a língua. Hoje, vários Djeoromitxí ensinam em português e na sua língua materna nas escolas de ensino fundamental da reserva Guaporé, usando a ortografia prática e o material de alfabetização desenvolvidos por Nádia Pires. Na T. I. Rio Branco, Djeoromitxí continua sendo falado somente por um punhado de indivíduos. Embora haja ainda duas pessoas que falam a língua Arikapú, a língua não é mais usada, visto que uma dessas pessoas reside na T. I. Rio Branco, enquanto a outra reside na T. I. Guaporé. Quando morrerem estas duas pessoas, a língua Arikapú será extinta, já que não houve transmissão às gerações sucessoras. A maioria daqueles que falam Djeoromitxí também fala português e alguns falam outras línguas. A maioria dos (descendentes de) Arikapú na T. I. Rio Branco fala Tuparí, além de português, e na T. I. Guaporé fala-se Makuráp. Uma das duas pessoas que falam Arikapú também fala Djeoromitxí, Makuráp e português, enquanto a outra fala principalmente Tuparí, além de Djeoromitxí e um pouco de português. A maioria dos empréstimos nas línguas Jabutí veio de Makuráp, que funcionava como uma língua geral durante a época da borracha (Snethlage, 1937; Sekelj, 1950; Caspar, 1975).

As línguas Jabutí são bastante diferentes das outras línguas da região do Guaporé e não fazem parte das famílias lingüísticas vizinhas Tupí, Nambikwara ou Txapakura. Possivelmente por este motivo, as línguas Jabutí são consideradas, muitas vezes, como uma família pequena, isolada e sem afiliação a qualquer outra família lingüística conhecida. Porém, tão cedo como em 1935, Nimuendajú (2000) observou que as listas de palavras Arikapú e Djeoromitxí coletadas

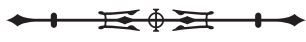


por Snethlage em 1934 revelaram semelhanças com certas línguas Jê do Brasil oriental, tais como Xerente, Kayapó, Kaingáng e Timbira. Pesquisas recentes de Ribeiro e van der Voort (2005, no prelo) fornecem evidências lexicais e gramaticais adicionais que confirmam a hipótese de Nimuendajú. Assim, a família lingüística Jabutí, provavelmente, representa um braço do tronco lingüístico Macro-jê.

As línguas Jabutí são muito semelhantes entre si, porém não são idênticas. Visto que os Arikapú e os Djeoromitxí são vizinhos próximos, é provável que suas línguas tenham se diversificado de uma língua ancestral comum, na mesma região. É menos provável que esta diversificação tenha ocorrido fora da região e que depois as duas línguas migraram juntas. Isto implica que a distância temporal entre as línguas Arikapú e Djeoromitxí indicará o tempo mínimo que as duas existem na região do Guaporé. Uma comparação preliminar, que mostra aproximadamente 58\% de retenção lexical na lista básica Swadesh de 100 itens, sugere que levou mais de 1800 anos para que as duas se diferenciassem até chegar ao que são hoje. Os ancestrais dos Jabutí, portanto, devem ter migrado à região do Guaporé pelo menos dois mil anos atrás e possivelmente vieram do leste, visto que falavam uma língua Macro-jê.

Antes de relatar a tentativa de reconstruir o Proto-Jabutí, as características básicas das línguas Arikapú e Djeoromitxí serão descritas nas seguintes subseções. Tanto a reconstrução quanto os esboços descritivos são baseados em dados coletados entre 2001 e 2004 nas reservas indígenas Rio Branco e Rio Guaporé'.

\section{Características básicas da língua Arikapú}

Os fonemas vocálicos da língua Arikapú incluem oito vogais orais e seis vogais nasais. A língua tem dez fonemas consonantais. Os fonemas estão representados por símbolos do IPA na Tabela 1:

Tabela 1. Fonemas Arikapú.

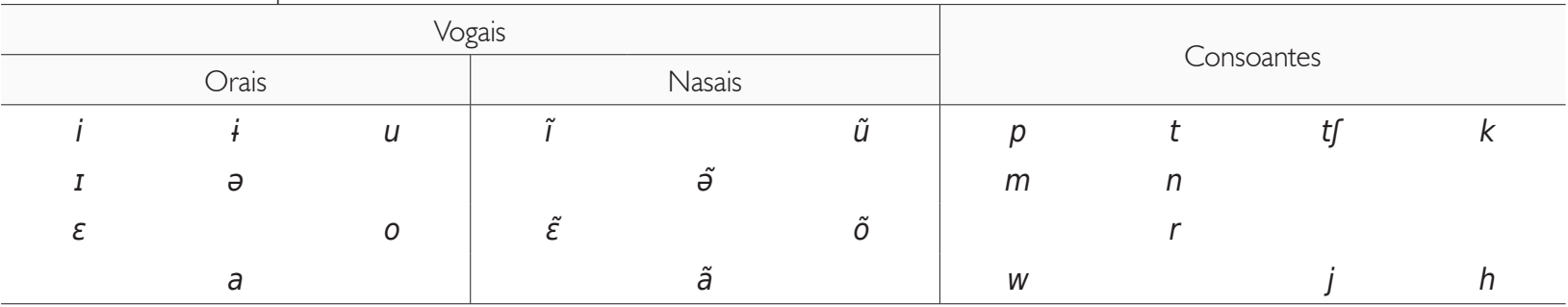

O status contrastivo das vogais nasais é confirmado por pares mínimos, como nĩkra 'cadeira' vs. nĩkrã 'pulso', takə 'está quente' vs. takã 'está pronto', tari 'limpar roça' vs. tarĩ 'está seco' e ku 'comer' vs. kũ 'ir embora'. Mesmo assim, existe variação entre pronunciação nasal e oral: há desnasalização de $/ \tilde{\varepsilon} /$ no ambiente $/ n \_$e há espalhamento de nasalidade para esquerda (veja os parágrafos sobre $/ \mathrm{m} / \mathrm{e} / \mathrm{n} /$ nesta seção).

Existem ditongos na língua, alguns foram encontrados em contraste com combinações de vogais pertencendo a sílabas diferentes, como em ['kaj] /kaj/ 'cabeça' vs. [ka.'i] /kai/ 'cabelo, pêlo, penas'. O /j/ ocorre também no onset silábico, em palavras como mujo 'borduna comprida', kuju 'asa, pena', rajo 'tio'. Além disso, existem alguns casos

\footnotetext{
Sendo concebido depois do último período no campo e, conseqüentemente, escrito longe do acesso a falantes nativos, este artigo representa trabalho em andamento sujeito a erros e sofrendo lacunas. Comentários críticos sobre todos os aspectos são sempre muito bem-vindos e contribuirão a uma obra mais abrangente planejada para o futuro próximo.
}

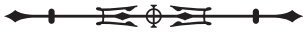




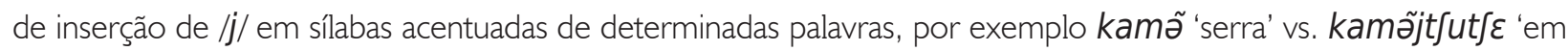
cima da serra', kũ 'moer' vs. îhãkũj 'moer caroços' e inũtõ(j)nõ 'estou dormindo'.

$\bigcirc$ acento principal da palavra está na última sílaba da raiz lexical.

Existem também combinações de consoantes, como /pr, $k r, m r /$, embora a sua distribuição seja limitada. Combinações de consoantes ainda menos comuns são /pw, kw, mw, pj, nj, wr, rn/.

Há algumas alternâncias alofônicas de consoantes. A mais comum envolve o fonema $/ \mathrm{m} /$, cujos alofones [b] e [mb] estão em variação livre antes de vogais orais, como em /miku/ [bi'ku] [mbi'ku] 'terreiro'; /mo/ [bu] [mbv] 'flecha'. Se /m/ está entre duas vogais, a primeira vogal é freqüentemente nasalizada, como em /kamu/ [kã'bu] $\sim$ [kam'bu] 'jovem'; /kra-mrə/ [krã'brə] [kram'brə] 'miçanga' (lit. 'pequena-pedra').

O fonema $/ n$ / se comporta conforme um padrão similar. Antes da maioria das vogais orais, $/ n /$ tem alofones [d] e [nd] em variação livre. Na posição intervocálica, o /n/ pode causar nasalização da vogal à esquerda, como em /nuní/ [ndun'di $] \sim[$ dun'dit] [dũ'dit] 'peito, seio'.

Observe que $/ \mathrm{m} /$ e $/ \mathrm{n} /$ também estão representados pelos alofones respectivos [m] e [n]. Estes alofones ocorrem geralmente na posição antes de vogais nasais e estão em distribuição complementar com [b/mb] e

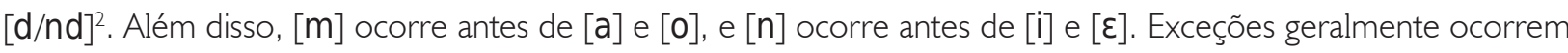
em empréstimos, por exemplo, o [m] pode ocorrer no início da palavra, antes de uma vogal oral, em /miaku/ [bia'ku] [mia'ku] 'jabutî'. Provavelmente, esta palavra vem do Makuráp, uma língua Tuparí, que também não tem uma distinção fonêmica entre [m] e [b]. Existem outras raras ocorrências de [m] antes de uma vogal oral, mas, uma vez que não há pares mínimos e que aquela vogal pode ser livremente (re-)nasalizada, analiso que ela seja provavelmente resultado de desnasalização.

$\mathrm{O}$ [d3] provavelmente não representa um fonema distinto, visto que ocorre somente antes de [i] e não contrasta com [d] nesta posição. Embora o [n] ocorra também antes de [i], este [i] está em variação livre com [ĩ] nasal (/ĩ) na mesma posição. Por isso, considero todos os três como alofones de $/ n / . \bigcirc$ [d3] é muito raro, mas dois casos, nihã ['dzihã] 'esse' e niri [dzi'ri] 'raiz', ocorrem no Apêndice (98, 221).

Há alternância entre os fonemas /t / / e /h/, que ocorrem em variação livre em certas palavras específicas, como

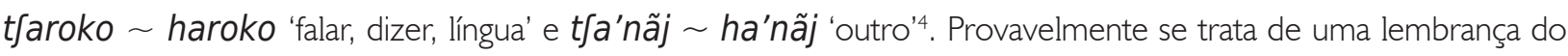
mesmo tipo de alternância que está ainda produtivo em Djeoromitxí, a de /r/e /h/ (veja Características básicas da língua Djeoromotxí). Além disso, há variação livre entre presença e ausência de /t J/ em certas palavras específicas, como em $i \sim t$ ti 'osso' e pəa pətfa 'formar, tecer'.

O [?] provavelmente não representa um fonema, mas um efeito fonético opcional na fronteira de duas vogais, obrigatório no início de palavras que começam por vogal. Isto é provavelmente motivado pela estrutura silábica preferida CV.

\footnotetext{
2 Seria, com igual razão, possível representar [m], [(m)b], [n] e [(n)d] como alofones de unidades fonêmicas /b/e /d/, em vez de /m/e /n/. Na ortografia prática, a distinção entre $[\mathrm{m}]$ e $[(\mathrm{m}) \mathrm{b}]$ e $[\mathrm{n}]$ e $[(\mathrm{n}) \mathrm{d}]$ é preservada, respectivamente como $<m>$ vs. $\langle b>$ e $<n>$ vs. $<d>$.

3 bzicku em Djeoromitxí.

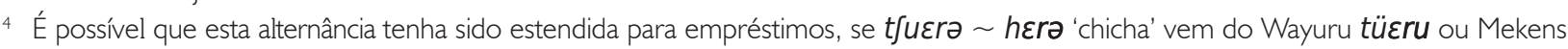

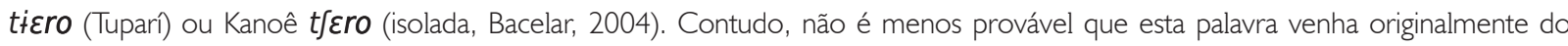
Arikapú. A forma <averú> registrada por Fawcett (Rivet, 1953) sugere que a palavra é analisável em Arikapú. Por outro lado, a minha

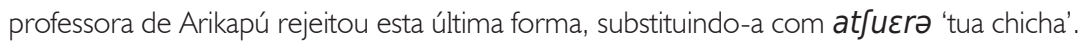


Observe que o $/ \mathrm{k} /$ muitas vezes é aspirado como [kh] na posição antes da vogal central /ə/. Os sons $/ \mathrm{k} / \mathrm{e} / \mathrm{t} / \mathrm{estão} \mathrm{em}$

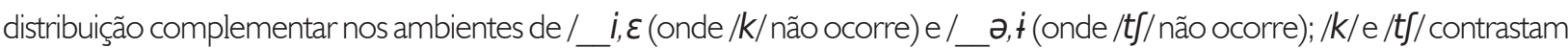
diante de / a,o, u e, portanto, são considerados fonemas diferentes, mesmo diante das vogais anteriores e centrais.

As categorias lexicais do Arikapú são substantivos, verbos, advérbios e partículas gramaticais. Não há diferença formal entre adjetivos e verbos intransitivos. A ordem das palavras na sentença parece ser bastante livre, mas as ordens encontradas mais freqüentemente são Substantivo-Modificador e Sujeito-Objeto-Verbo ou Objeto-Verbo-Sujeito. Uma vez que os falantes não produzem diálogos ou textos, é difícil decidir se a configuracionalidade do Arikapú não se deve a processos de obsolescência ou a influência de línguas vizinhas, especialmente Djeoromitxí, que os falantes de Arikapú dominam também.

Com respeito à morfossintaxe, o Arikapú é uma língua isolante e não tem morfologia complexa. Há um pequeno número de prefixos pessoais obrigatórios, que são aplicados de acordo com um padrão parcialmente ergativo. Não há marcação de caso, mas há um grupo de elementos posposicionais (também analisável como clíticos ou sufixos). A distribuição dos elementos usados para referência pessoal está resumida na Tabela 2:

Tabela 2. Distribuição de marcadores pessoais em Arikapú.

\begin{tabular}{|c|c|c|c|c|c|c|}
\hline & \multirow{2}{*}{ Pronomes } & \multirow{2}{*}{ Possessivo } & \multirow{2}{*}{ Intransitivo } & \multicolumn{2}{|c|}{ Transitivo } & \multirow{2}{*}{ Forma clítica do Sujeito } \\
\hline & & & & Sujeito & Objeto & \\
\hline ISG & $i h \varepsilon$ & $i-$ & $i-$ & ihe & $i-$ & $=n \tilde{~}$ \\
\hline 2 & ahe & $a-$ & $a-$ & ahe & $a-$ & $=n \varepsilon$ \\
\hline 3 & & $i-$, ta-, tfi-, N & ta-,$i-$ & $N$ & $i-, t \int i-, t \int \varepsilon-, N$ & \\
\hline $\begin{array}{l}\text { PPL } \\
\text { impess. }\end{array}$ & tfihe & $\begin{array}{c}t \int i- \\
i-, t f i-, a-\end{array}$ & $\begin{array}{c}t \int i- \\
i-, t \int i-\end{array}$ & & $\begin{array}{c}t \int j- \\
i-, t 5 i-, t \int \varepsilon-\end{array}$ & $(=n \tilde{)})$ \\
\hline
\end{tabular}

O prefixo da primeira pessoa é homófono com um dos prefixos da terceira pessoa. Uma vez que não está claro se se tratam de morfemas diferentes, estes estão sempre glosados como '1sG/3'. Como prefixo da terceira pessoa do sujeito, i- ocorre somente com certos verbos de conteúdo semântico adjetival. Geralmente, é o prefixo da terceira pessoa ta- que refere ao sujeito do verbo intransitivo ${ }^{5}$. $\bigcirc$ uso de $t \int i$ - e $t \int \varepsilon$ - como marcadores de terceira pessoa é difícil de distinguir do uso como marcadores impessoais ou de referência genérica. A terceira pessoa não ocorre como prefixo pessoal se já está expressa por um substantivo ( $N$ na Tabela 2).

Quando aplicados a substantivos, os prefixos pessoais têm um significado possessivo, como no exemplo (1). Quando aplicados a verbos, exprimem um argumento estrutural, como em (2):

(1) a-nĩrõ

2-moradia

'tua casa'
(2) ta-pi

3-bêbado

'Está bêbado.'

5 O possuidor de terceira pessoa, quando expresso pelo prefixo ta-, é coreferencial com o sujeito, da mesma forma que ocorre com elementos similares em várias línguas do tronco Macro-Jê (Rodrigues, 1986, p.55). 
Quando aplicados a verbos intransitivos, os prefixos referem ao sujeito; e a verbos transitivos, os prefixos referem ao objeto, como nos exemplos (3) e (4):
(3) $a h \varepsilon=n \varepsilon$
i-ãrã-tã
você $=2 \mathrm{~s}$
1sG/3-ver-NEG
(4) tfi-koni-wiro
1PL-flechar-FUT
'Nem olha para mim!'
'Vai flechar nós.'

Além de prefixos, Arikapú também tem enclíticos que concordam com a primeira ou a segunda pessoa do sujeito de sentenças declarativas, interrogativas e raramente imperativas. Estão sempre aplicados no final do primeiro constituinte da sentença (exceto quando o primeiro constituinte representa o objeto). Observe as ordens alternativas em (5) e (6):
(5) $\quad i$-prəj=nõ
1sG/3-chegar $=1 \mathrm{~s}$
'Eu vim para te ver.'
a-ãrã
2-ver

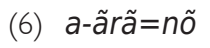
2-ver $=1 \mathrm{~s}$
i-prəj
1sG-chegar
'Eu vim para te ver.'

Os prefixos de primeira pessoa singular e plural ocorrem também em uso impessoal e neste uso são difíceis de distinguir da terceira pessoa, como mostram os exemplos (7) e (8):
(7) i-kum̃̃
(8) $i h \varepsilon=n \tilde{~}$
tรi-ãrã
1sG/3-pesado
eu $=1 \mathrm{~s}$
1PL-ver
'Está pesado?'
'Eu vi eles.'

Note que o uso de pronomes pessoais é opcional e tem funções pragmáticas.

Argumentos locais são indicados por uma variedade de sufixos diferentes, que expressam papéis como aversivo -rijj, dativo -ri, instrumental -nə, locativo - $t \int \varepsilon$, similativo -rõ, comitativo - pakəj e ablativo -kunĩ, como em (9) e (10):
(9) ti-pakəj
t $\int i-m \partial t ;$
rede-comIT
PPL-plantar
(10) nũrõ-kunĩ
mato-ABL
ta-t $\int u r i$
3-entrar
'Enterrou ele com/na rede.'
'Ele chegou do mato.'

Além de morfologia flexional, a língua também possui elementos que, por enquanto, considero como sufixos

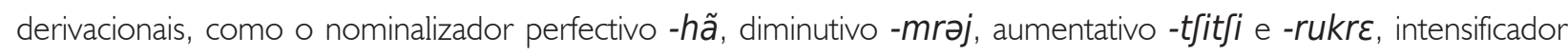

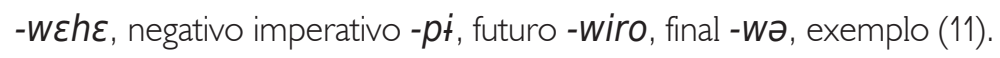




\begin{tabular}{|c|c|c|}
\hline (11) tfitfi-hã & kari-hã & iro $=n \tilde{~}$ \\
\hline milho-caroço & Seco-NOM & querer $=1 \mathrm{~s}$ \\
\hline
\end{tabular}

O exemplo (11) também mostra um elemento que se assemelha a um classificador nominal, -hã 'caroço, semente'. Trata-se de um substantivo obrigatoriamente possuído e ocorre sempre com prefixo pessoal ou como segundo elemento numa composição nominal ou incorporação verbal. Outros substantivos deste tipo

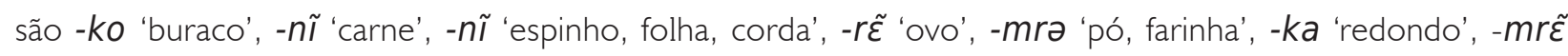
'mingau, bagaço', $-r \varepsilon$ 'verme', $k \partial$ 'couro, casca' e nũ 'mingau, massa', embora estes dois últimos também ocorram independentes. Estes substantivos são reconstruíveis para Proto-Jê, com exceção de -ka 'redondo', - $m r \tilde{\varepsilon}$ 'mingau, bagaço' e $-r \varepsilon$ 'verme' (Ribeiro, c.p.). Formas muito similares, com sentidos similares, foram encontradas também em outras línguas da região, como - $m \tilde{\varepsilon}$ 'mingau' e -nĩ 'espinho' em Kwazá (isolado) e -nũ 'pó' em Aikanã, Kanoê e Kwazá (isolados) e nas línguas Nambikwara, onde funcionam como elementos classificadores gramaticais (van der Voort, 2005, p. 397). Algumas destas semelhanças talvez se devam à difusão areal de origem Macro-Jê (veja seção Morfossintaxe).

O exemplo (11) mostra ainda que o enclítico de sujeito não está aplicado ao objeto da sentença (mesmo que este ocorra no primeiro lugar). Isto implica na possibilidade de se considerar a combinação de objeto e predicado como um único constituinte sintático.

\section{Características básicas da língua DJeOromitxí}

Os fonemas vocálicos da língua Djeoromitxí incluem sete vogais orais e quatro vogais nasais. A língua tem 12 fonemas consonantais ${ }^{6}$. Os fonemas estão representados por símbolos do IPA na Tabela 3:

Tabela 3. Fonemas Djeoromitxí.

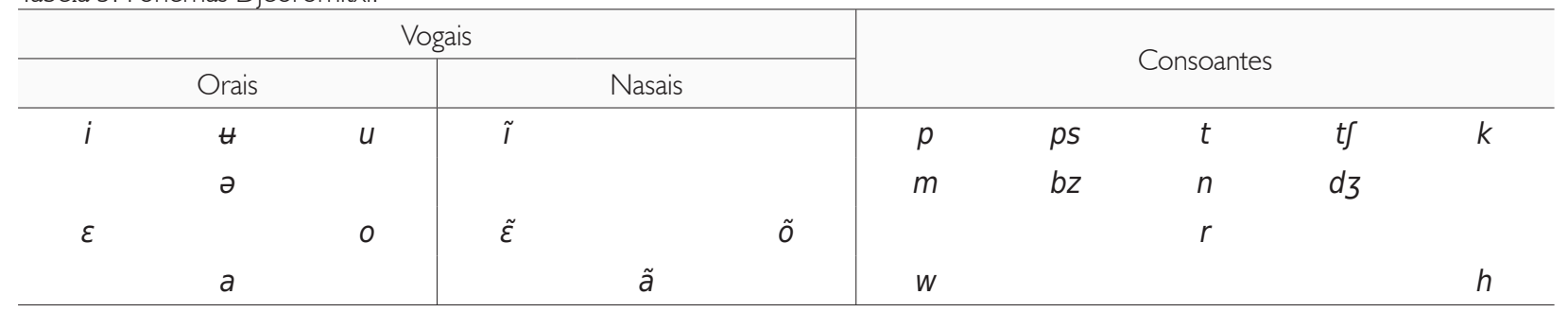

A vogal central fechada / $t$ / é freqüentemente pronunciada como [ø].

Não há ditongos em Djeoromitxí e combinações de vogais adjacentes sempre pertencem a sílabas diferentes. A oclusão glotal [?] representa um efeito fonético opcional que ocorre no encontro de duas vogais. $\bigcirc$ acento principal recai na última sílaba da palavra.

6 De acordo com Pires (1992), o sistema consonantal tem 14 fonemas. Mesmo que os dados e as análises de Pires sejam fidedignos e sistemáticos, novos dados de campo me levaram a uma outra análise, que, por exemplo, não dá status fonêmico a [b] e [d].

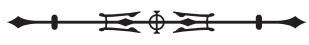


Embora os dados não estejam tão completos e o assunto mereça mais pesquisa, assumo que Djeoromitxí é basicamente similar a Arikapú no sentido de que não tem contraste fonêmico entre $[b]$ e $[\mathrm{m}]$ e $[\mathrm{d}]$ e $[\mathrm{n}]$. A distribuição de $[\mathrm{b}]$ e [d] versus [m] e [n] está quase complementar; os sons [b] e [d] ocorrem exclusivamente antes de vogais orais, enquanto $[\mathrm{m}]$ e $[\mathrm{n}]$ ocorrem antes de vogais nasais ou vogais orais sob desnasalização ${ }^{7}$.

A africada /bz/ ocorre somente num ambiente específico, antes da vogal anterior fechada/i/, onde contrasta com

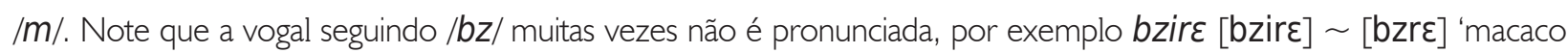
prego'. Veja também as observações com respeito a /bz/ e *m na seção As consoantes. Por falta de pares mínimos, o status de /ps/ está menos decidido, mas contrasta com /p/ no mesmo ambiente.

$\bigcirc / d z /$ representa um fonema com uma distribuição muita limitada. Na ortografia prática criada pelos Djeoromitxí e Nádia Pires, está escrito digraficamente como $\langle d j\rangle$, similar ao /t $\int$, que é escrito como $<t x>$ (Pires et al., 1994, 1995).

Observe que na posição antes da vogal fechada arredondada central $[\mathrm{H}]$ o / $/ \mathrm{k} /$ é pronunciado como [q]. Antes da vogal central / $/$ / e da vogal posterior / $/$ /, o / $/$ / é freqüentemente aspirado como [kh]. Antes de vogais posteriores e $[\mathrm{H}]$, o /p/ é geralmente realizado como um fricativo bilabial $[\phi]$ ou como um africado $[\mathrm{p} \phi]$.

Dos dados de Pires (1992), deduz-se que o/k/ ocorre, além de em outros ambientes, também no ambiente /__i.i. Por enquanto, o /t J/ não foi encontrado no ambiente /__.

O glide $/ W /$ é pronunciado como $[ß]$.

Existe uma alternância morfofonológica que caracteriza o Djeoromitxí. Quando palavras com /h/ no início são precedidas por prefixos pessoais, ou ocorrem como segunda parte em uma composição, o $/ \mathrm{h} /$ inicial é substituído por $/ r /$. Observe os exemplos de (12) e (17):

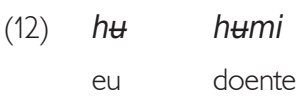

'Estou doente.'

(15) hamə

cansado

'Ele está cansado.'
(13) $h t$

eu pé $=$ doente

'Meu pé dói.'

(16) ht hamə

eu cansado

'Estou cansado.'
(14) hõmska=rumi

cabeça $=$ doente

'Estou/está com dor de cabeça.'

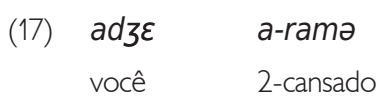

'Você está cansado.'

Pires (1992, p. 46) mostra dados que indicam a existência de uma alternância morfofonológica similar entre $/ h /$ e $/ n$ / em certas raízes. As alternâncias morfofonológicas lembram um fenômeno parecido em línguas Macro-Jê e Tupí-Guaraní, que foi chamado de 'prefixo relacional' ou 'marcador de (não-)contigüidade' na literatura recente sobre línguas Macro-Jê e Tupí (Rodrigues, 1999; Seki, 2000). No entanto, nesta fase da pesquisa, esta análise não foi adotada.

7 O par mínimo dado por Pires (1992, p. 37) como evidência da oposição entre [d] e [n] contém uma palavra emprestada do Makuráp: $<$ doko > 'poraquê' (MAK ['nduku], DJE mirctfitfi) e uma frase não-analisada < noko> 'comer' (/nõ ku/, lit. 'comer comida').

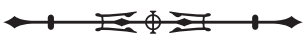


Com respeito à gramática, Djeoromitxí é muito similar a Arikapú. Possui as mesmas categorias lexicais: substantivos, verbos, advérbios e partículas gramaticais, e não distingue adjetivos de verbos intransitivos. Na frase nominal, a ordem mais freqüente das palavras é também Substantivo-Modificador. Na frase verbal, a ordem ObjetoVerbo é fixa e o fato de que nenhum constituinte pode ser inserido entre eles sugere que o objeto e o verbo juntos formam um único constituinte sintático. O Sujeito pode ocorrer no início ou no final. Como os dados de Djeoromitxí são de uma comunidade de talvez 50 falantes ativos, estão provavelmente menos suscetíveis a fenômenos de obsolescência que os dados Arikapú.

A morfologia inclui prefixos pessoais obrigatórios, embora as formas difiram um pouco de Arikapú. A marcação de pessoa segue um padrão ergativo. Em princípio, o uso de pronomes pessoais é opcional. Não existem, diferentemente de Arikapú, enclíticos de sujeito. Ver Tabela 4.

Tabela 4. Distribuição de marcadores pessoais em Djeoromitxí.

\begin{tabular}{|c|c|c|c|c|c|}
\hline & \multirow{2}{*}{ Pronomes } & \multirow{2}{*}{$\begin{array}{l}\text { Possessivo, } \\
\text { Preposição }\end{array}$} & \multirow{2}{*}{ Intransitivo } & \multicolumn{2}{|c|}{ Transitivo } \\
\hline & & & & Sujeito & Objeto \\
\hline 1SG & $h t$ & & & $h t$ & \\
\hline 2 & $\operatorname{adz\varepsilon }$ & a- & $a-$ & $\operatorname{adz\varepsilon }$ & $a-/ a d z \varepsilon$ \\
\hline 3 & na & $i-/ N$ & $i-$ / na / N & na / N & $i-/ N$ \\
\hline 1PL & hirt & $h i-$ & hi- & hirt & $h i-$ \\
\hline
\end{tabular}

Em Djeoromitxí, a primeira pessoa singular não é marcada, enquanto a primeira pessoa plural e a segunda pessoa são marcadas por prefixos obrigatórios. A terceira pessoa é marcada por um prefixo sob a ausência de um substantivo ( $N$ na Tabela 4) ou um pronome na função de argumento ou possuidor. Se o possuidor ou o argumento não está expresso por um substantivo (ou, no caso de um verbo intransitivo, um pronome), o uso de um prefixo pessoal é geralmente obrigatório (mas há exceções, como (15)). Sujeitos de verbos transitivos não são marcados por prefixos. Os exemplos (18) e (19) mostram o uso possessivo ${ }^{8}$ de prefixos pessoais:
(18) nikt
(19) $a-k \partial$
roça
2-couro
'roça', 'minha roça (com milho)'
'suas roupas'

Os exemplos (20) e (21) mostram o uso dos prefixos pessoais para indicar o sujeito do verbo intransitivo. A primeira pessoa singular não é marcada:

\footnotetext{
${ }^{8}$ Em Djeoromitxí há, ao contrário de Arikapú, um elemento possessivo opcional, $d$ dzEw $t$ t $\int a$, que provavelmente está sendo usado para ênfase e em caso de ambigüidade. Sem este elemento, pode existir ambigüidade em determinados contextos entre o substantivo neutro e o substantivo possuído por uma primeira pessoa.
}

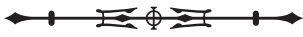



(20) $h t$
haktme
(21) hirt
hi-hõrahi
eu bocejar
nós 1PL-bêbado
'Estou bocejando.'
'Estamos todos bêbados.'

Nos verbos transitivos, os prefixos pessoais indicam o objeto. A terceira pessoa é marcada pelo prefixo $i-$, como nos exemplos (22) e (23):

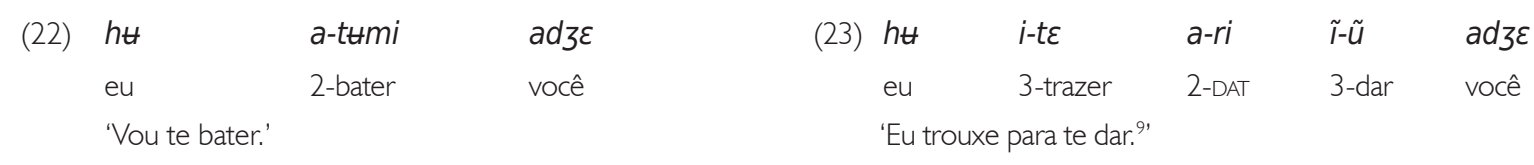

O uso impessoal de prefixos foi também atestado em Djeoromitxí, mas não tão claramente como em Arikapú. Os casos mais evidentes envolvem o uso impessoal possessivo do marcador de primeira pessoa plural -hi, como em (24) e (25):
(24) hi-bzia
(25) uruku bzia
roça dono
1PL-dono
'o dono dele'
'o dono da roça'

Argumentos locais são indicados pelos seguintes elementos posposicionais ${ }^{10}$ : agentivo $m \varepsilon$, beneficiário $\varepsilon n i$, dativo $r i$, instrumental ə, locativo $t \int \varepsilon$, comitativo pakə e ablativo kuni, como em (26) e (27):

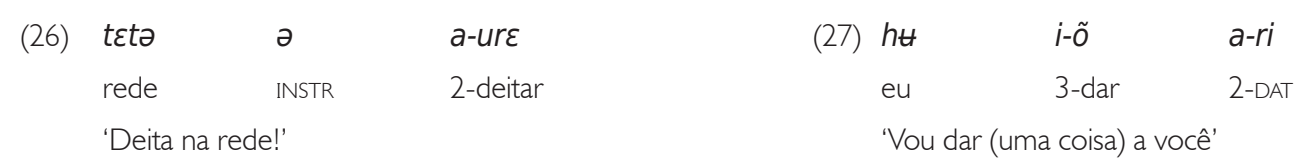

Djeoromitxí também possui elementos que podem ser considerados como sufixos derivacionais, como o nominalizador -t $\int$ i, diminutivo -titi (Pires, 1992, p. 64), aumentativo -t $t i t \int i$ e intensificador -wehc. Além disso, existem elementos gramaticais sobre os quais é difícil dizer se são partículas livres ou morfemas presos, como o negativo tõ, interrogativo $h i$, futuro ma, passado $t \int \varepsilon$ e nominalizadores $a$, hə, e ə (Pires, 1992). $\bigcirc$ exemplo (28) mostra o nominalizador adjetival (que cria um substantivo com função atributiva) hə:

\footnotetext{
9 A ordem alternativa 34512 foi registrada também.

10 Veja também Pires (1992, p. 74-75, 108-110).
}

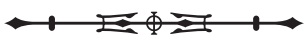




\section{(28) tfitfi-hõ kuri-hə ũ \\ milho-caroço seco-NOM dar \\ 'Me dá milho torrado.' (literalmente: 'dá caroços de milho seco')}

Finalmente, há elementos que lembram classificadores nominais, como - $d z \varepsilon$ 'ovo', - $h o ̃$ 'semente, caroço', ilustrado pelo exemplo (28), -ka 'redondo', kə 'couro, casca', -k甘 'buraco', -mã 'mingau', -nĩ 'carne', -nĩ 'espinho, folha, corda', -tə 'pequena', - $r \varepsilon$ 'verme' e -tu 'pó, farinha'. Pires (1992, p. 58-59) analisou alguns destes elementos como segunda parte de um substantivo composto; não obstante, eles não ocorrerem independentes (com exceção de kə 'couro, casca'). Eles podem diacronicamente ser derivados de substantivos, mas para expressar o conteúdo semântico do elemento classificador numa forma independente, geralmente precisam do prefixo i-, como em ĩhõ 'caroço', ik甘 'buraco'. Os elementos classificadores de Arikapú e Djeoromitxí formam uma categoria pequena e geralmente não muito produtiva (veja também as observações nas seções As vogais e Características básicas da língua Arikapú).

\section{RECONSTRUÇÃO DA PROTO-LÍNGUA}

Como foi visto nas seções anteriores, Arikapú e Djeoromitxí são línguas bastante parecidas no que tange à fonologia e à gramática. O léxico também sugere uma relação estreita entre as línguas. O fato de uma grande parte do vocabulário básico ser cognata, por correspondências fonológicas sistemáticas e, conseqüentemente, ser reconstruível para a protolíngua, representa evidência convencional que a relação entre estas línguas é de parentesco. Na seção seguinte farei uma tentativa de reconstruir a fonologia, morfologia e uma parte do léxico do Proto-Jabutí, de acordo com o método comparativo explicado em, por exemplo, Bynon (1983), Campbell (1998), Hock (1991), Jeffers e Lehiste (1992).

\section{O LÉXICO E O SISTEMA FONOLÓGICO}

O banco de dados lexicais que constitui o fundamento deste estudo contém aproximadamente 1.410 raízes únicas de Arikapú e 1.095 raízes únicas de Djeoromitxí. Entre estes, mais ou menos 1.085 pares de entradas eram comparáveis. Depois de excluir pares sem semelhança nenhuma, prováveis empréstimos e formas obviamente onomatopaicas, sobraram cerca de 500 pares de cognatos possíveis. Baseando-me em correspondências entre fonemas em posições similares nas formas, foi possível reconstruir aproximadamente 200 proto-formas completamente (Apêndice), além do sistema fonológico ancestral. Note que os dados são escassos para certas correspondências, as quais, conseqüentemente, são ainda bastante especulativas. Estas correspondências foram, mesmo assim, incluídas neste trabalho para levantar uma primeira proposta do quadro fonológico da proto-língua e para indicar caminhos para futuras pesquisas. Na representação das correspondências de fonemas e de formas no texto, está mencionado em primeiro lugar Arikapú e em segundo lugar Djeoromitxí, em letras cursivas, nesta maneira: Arikapú:Djeoromitxí. Fonemas e formas reconstruídos para Proto-Jabutí são precedidos por um asterisco (*).

\section{As vogais}

A Tabela 5 resume as correspondências fonêmicas vocálicas entre Arikapú e Djeoromitxí e sua reconstrução em ProtoJabutí. Os ambientes valem para Proto-Jabutí. Os números referem aos pares de cognatos e as suas reconstruções que ilustram estas correspondências no Apêndice. Cognatos que não representam evidência forte estão mencionados entre parênteses.

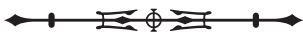


Tabela 5. Correspondências vocálicas e reconstruções.

\begin{tabular}{|c|c|c|c|c|}
\hline PJab & Ari & Dje & Ambientes PJab & Número no Apêndice \\
\hline *a & a & a & $/ \#, k, p, t \int, r, w$ & $\begin{array}{l}3,8,20,25,27,35,44,45,51,53,55,56,65,72,73,94,111,115,121,134,138,142, \\
(147), 148,155,160,161,168,170,176,180,183,191192,205,208,209,222,224,236, \\
238,(240), 242,244,246,254,259,264\end{array}$ \\
\hline *a & a & $\boldsymbol{\theta},(\mathbf{u})$ & $/ \#, t\rceil, r$ & $95,96,110,186,199,(229), 258$ \\
\hline *a & a & $\varepsilon$ & I_j\# & $18,37,50,118,193$ \\
\hline * $\varepsilon$ & $\varepsilon$ & $\varepsilon$ & $/ h, m, p, t\}, t, r, w$ & $2,16,42,67,79,92,94,132,134,135,138,139,145,146,151,182,260$ \\
\hline *i & i & $\mathbf{i}$ & $/ \#, h, m, p, t\}, t, d_{3}, r, w_{-}$ & $\begin{array}{l}5,7,15,20,40,42,48,51,63,64,80,81,83,89,95,104,105,109,112,113,119,124, \\
125,129,134,136,137,148,149,150,176,179,185,194,205,206,208,219,222,236 \\
241,243,253,257\end{array}$ \\
\hline *I & $\mathbf{I}$ & i & $/ m, w_{-}$ & $41,120,212$ \\
\hline *i & i & i & $/ \#, k, m, p, t, r$ & $2,4,6,30,78,97,122,128,142,(161), 226,230,239,256,259$ \\
\hline *ə & ə & ə & $/ k, m,[p$ átono $]$ & $\begin{array}{l}3,37,44,50,52,53,73,74,77,108,115,118,126,131,138,141,153,159,187,195 \\
208,210,212,225,255\end{array}$ \\
\hline 米 & ə & $\varepsilon$ & $1 t\}, n, t, r$ & (11), 39, 54, 64, 67, 81, 100, 113, 144, 145, 149, 160, 197, 216, 218, 223, 238, 248, 262 \\
\hline *ə & ə & i & l j\# & 197, 254 \\
\hline *o & $\mathbf{0}$ & 廿 & $/ \#, k, p, t \int, t, r$ & $4,19,22,25,32,36,60,76,85,89,104,106,109,141,162,201,210,213,219,229,255,261$ \\
\hline *u & $\mathbf{u}$ & $\mathbf{u}$ & $/ \#, k, m, n, p, t f, h$ & $\begin{array}{l}7,9,10,13,14,16,(17), 22,30,31,37,39,43,45,46,47,48,54,55,61,69,70,74,75, \\
76,92,96,104,112,119,122,126,129,130,135,136,137,147,148,151,152,154,156, \\
162,166,176,180,200,205,206,214,236,241,251,254,256\end{array}$ \\
\hline * u & $\mathbf{u}$ & $\mathbf{0}$ & $/ k, n, t \int_{-}$ & $(10), 17,(130), 230$ \\
\hline$* \mathbf{u}$ & $\mathbf{u}$ & $\mathbf{i}$ & $/ m_{-}(j \#)$ & 8,9 \\
\hline *ã & ã & ã & $/ m, t$ & $172,(247)$ \\
\hline *ã & ã & $\varepsilon$ & l j\# & $66,84,186$ \\
\hline *ã & ã & $\tilde{\varepsilon}$ & l j\# & 40,244 \\
\hline *ã & ã & $\tilde{0}$ & $/ h, r$ & $29,87,144,183,231,234,258$ \\
\hline * & $\tilde{\varepsilon}$ & $\varepsilon$ & $/ m, r$ & $46,139,(188), 235,242,265$ \\
\hline * $\tilde{\varepsilon}$ & $\boldsymbol{\theta}$ & $\tilde{\varepsilon}$ & $/ m r \_j \#$ & 10 \\
\hline 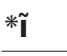 & $\tilde{\mathbf{i}}$ & ĩ & $/ m, n, r$ & $18,22,39,43,49,75,97,114,165,173,207,240$ \\
\hline 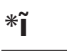 & ĩ & $\mathbf{i}$ & $/ n$ & $1,30,118,154$ \\
\hline 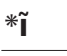 & $\mathbf{i}$ & $\tilde{\mathbf{I}}$ & $/ h$ & 178, (184) \\
\hline 粰 & $\tilde{\partial}$ & ĩ & $/ h, m, n, t, r$ & $(24), 68,93,130,153,200,213,245$ \\
\hline * $\tilde{\mathbf{f}}$ & $\tilde{\partial}$ & i & l_ j\# & 119 \\
\hline *õ & õ & $\mathbf{H}$ & $/ m_{-}$ & $59,72,195$ \\
\hline *õ & $\mathbf{0}$ & õ & $/ t, r$ & $21,43,60,86,206,253$ \\
\hline *õ & a & õ & $/ t, r_{-}$ & $13,17,178,199,233,237,251$ \\
\hline *õ & ə & õ & $/ t, r$ & $29,234,257$ \\
\hline *õ & $\tilde{\partial}$ & õ & $\ln , t, r$ & $91,121,175,249,252$ \\
\hline *ũ & $\tilde{\mathbf{u}}$ & $\tilde{\mathbf{o}}$ & $/ \#, k, n, r$ & $56,82,91,133,163,189,194,207,242,249,261$ \\
\hline *ũ & $\mathbf{u}$ & õ & $/ k, n, t$ & $31,123,161,243$ \\
\hline
\end{tabular}

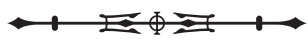


Algumas vogais se mostram bem estáveis, como a:a, i:i, ĩ:ĩ, ə:ə, $\varepsilon: \varepsilon, u: u$, das quais há bastante exemplos, incluindo os exemplos da lista básica de Swadesh. Algumas outras correspondências entre sons não idênticos necessitam de uma explicação. Alguns proto-fonemas foram reconstruídos com base em somente poucos pares de cognatos. Conseqüentemente, estes fonemas de ocorrência rara não representam evidência tão forte para a proto-língua como os outros fonemas. Por outro lado, alguns destes cognatos são da lista básica de Swadesh, o que aumenta o seu valor como evidência.

Há alguns casos em que *a foi preservado como /a/ em Arikapú, mas, aparentemente, foi centralizado como /ə/em Djeoromitxí1".

Há correspondências, como a: $\varepsilon$, que ocorrem somente no ambiente do glide final / _ j\# e desapareceram em Djeoromitxí (veja Os glides). Além de a: $\varepsilon$, existe um caso duvidoso de a:i (140).

Uma das outras correspondências de sons não-idênticos é r:i. Em Arikapú o fonema /I/, de distribuição limitada, está em contraste com /i/. Em Djeoromitxí este contraste se perdeu, mas foi preservado um dos ambientes que levou um dos alofones antigos do / $\mathrm{m} /$ a status fonêmico: /bz/ (veja também as observações com respeito a *m e Djeoromitxí /bz/ na seção As consoantes).

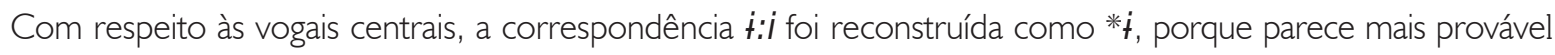
ter havido perda em Djeoromitxí do contraste com *i numa tendência geral de anteriorização vocálica, do que inovação em Arikapú de um /t//, que ocorre em quase todos os ambientes.

A correspondência ə: $\varepsilon$ ocorre em contraste com ə:ə e com $\varepsilon: \varepsilon$ em ambientes diferentes em Arikapú e Djeoromitxí. Porém, os ambientes em Proto-Jabutí mostram que esta correspondência ocorre somente depois de consoantes alveolares e alveopalatais (veja também nota 73), enquanto *ə, como proto-vogal da correspondência ə:ə, ocorre somente depois de consoantes bilabiais e velares. Uma vez que ${ }^{*} \varepsilon$, a proto-vogal da correspondência $\varepsilon: \mathcal{\varepsilon}$, ocorre em todos os ambientes, podemos concluir que a proto-vogal da correspondência $ə: \boldsymbol{\varepsilon}$ foi *ə. Essa vogal assimilou-se à posição anterior das consoantes alveolares e alveopalatais em Djeoromitxín .

A correspondência rara ə:i ocorre somente no ambiente do glide final / j\#.

Não há correspondências de sons idênticos envolvendo /O/. É provável que a correspondência O:t, que está quase sem exceções, vem do *o, representante de um fonema com maior ocorrência nas línguas do mundo que / $\boldsymbol{t} /$. Aparentemente, $\mathrm{O}$ * o sofreu anteriorização e levantamento em Djeoromitxí.

11 A maioria destes casos envolve (110) como raiz. A primeira sílaba do par krajtə:tarł 'grávida' (cuja primeira sílaba deve representar (110), mas cuja segunda sílaba neste momento não está analisável, nem reconstruível) em que a vogal não foi centralizada, sugere talvez que o mesmo fonema está envolvido. Com respeito ao par de cognatos karo:kurt 'seco' (229) pode ter ocorrido uma mudança do /ə/ para /u/ em Djeoromitxí em antecipação da vogal alta arredondada na próxima sílaba. Note também que na maioria dos casos o *a ocorre em posição não-acentuada, como em krajtfi:tədzi 'esposa' (95). Isso podia fornecer uma explicação para a centralização em Djeoromitxí se não tivesse exceções importantes, como kraj:tə 'filho, filha, filhote' (110) e mikraj:mitə 'inambu' (128).

12 Agradeço a Denny Moore (c.p.) por esta reconstrução. A maneira pela qual eu tinha chegado a esta conclusão se baseou num entendimento apenas parcial da situação; sob a hipótese de que a correspondência $k: t \int$ nos cognatos $(67,113,144,197,216,218)$ representa Proto-Jabutí

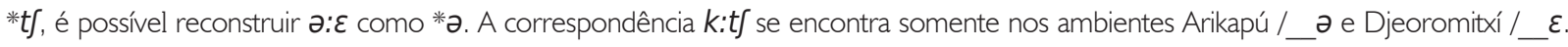
Uma vez que tf:t também se encontra no ambiente Djeoromitxí /__ $\varepsilon$, mas não se encontra no ambiente /__ $\partial$, nem em Arikapú nem em Djeoromitxí, podemos supor que nos cognatos $(67,113,144,197,216,218)$ deve ter ocorrido uma combinação de mudanças. Proto-Jabutí

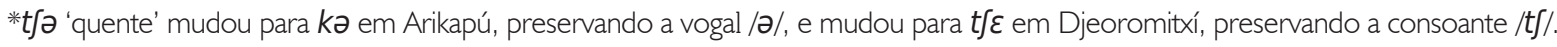

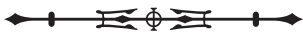


Para a correspondência muito rara $u$ :0, não existe uma explicação neste estágio da pesquisa e a sua reconstrução como *u foi proposta de forma provisória. A questão do fonema /o/ em Djeoromitxí necessita de mais trabalho de campo, entre outras coisas, em vista da variabilidade da pronunciação dos casos (10) e (130).

Possivelmente, existe uma correspondência $u$ :i no ambiente do glide final / j\#, mas, tendo somente dois exemplos (8,9), a evidência é fraca. Porém, o fato de o ambiente ser muito específico e as formas Djeoromitxí conterem /bz/, um traço especialmente característico para Jabutí, pode ser razão para considerar estes exemplos.

Com respeito às vogais nasais, as correspondências são mais complicadas do que entre as vogais orais. Existem somente poucas correspondências envolvendo /ã/. A correspondência ã:õ foi reconstruída como *ã, mas talvez poderia ser reconstruida alternativamente como *õ. A correspondência ã:ã foi registrada somente uma vez (talvez duas) e poderia ser reconstruída como reflexo de *ã, se valesse o esforço.

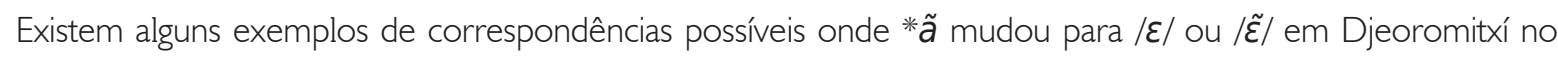
ambiente Proto-Jabutí /_ j\#.

Reconstrói-se a vogal $* \tilde{\varepsilon}$, que representa um fonema em ambas as línguas Jabutí, mas de ocorrência e distribuição bastante limitada. Na correspondência $\tilde{\varepsilon}: \varepsilon$, o fonema foi desnasalizado em Djeoromitxí. Na correspondência ə: $\tilde{\varepsilon}$ no ambiente de um glide final, a mesma nasalidade do $* \tilde{\varepsilon}$ foi preservada em Djeoromitxí, enquanto foi perdida em

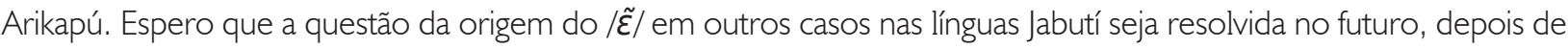
mais pesquisa de campo.

Ocorre desnasalização opcional de /î/ em Arikapú e Djeoromitxí. Conseqüentemente, os poucos casos de correspondência ĩ:i no ambiente de /n_ (neste caso, [n]) foram reconstruídos como *ĩ. Por outro lado, este ambiente é complementar com aquele do *i e uma pesquisa mais profunda, especialmente do Djeoromitxí, pode indicar *i como proto-fonema nestes casos (1, 30, 118, 154).

Existe um caso (178) da correspondência i:Ĩ no ambiente de /tf_ em Arikapú e /h_ em Djeoromitxí, que resulta provavelmente de desnasalização em Arikapú, porque também a vogal da primeira sílaba foi desnasalizada.

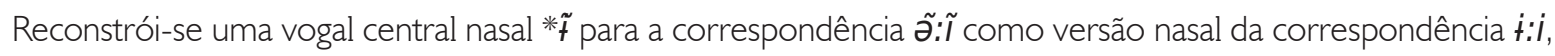
assumindo ${ }^{13}$ que ocorreu o mesmo processo de anteriorização em Djeoromitxí, mais um processo de abaixamento em

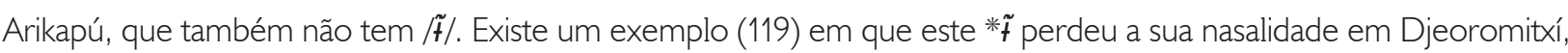
no ambiente de / j\#.

Ambos Arikapú e Djeoromitxí têm um fonema /õ/, mas nenhum caso de correspondência de sons idênticos foi registrado. A correspondência de /õ/em uma das línguas com um outro fonema na outra língua provavelmente pode ser explicada com desnasalização. Em Arikapú /õ/ representa um fonema com uma distribuição muito limitada (/m,n_). A correspondência õ: $甘$ ocorre somente no ambiente de $/ \mathrm{m} /$. Possivelmente, esta consoante foi desnasalizada (como [b]) em Djeoromitxí antigo antes da ascensão do *o para / $\mathbf{t} /$. A distribuição de /õ/ em Djeoromitxí é muito maior que em Arikapú (embora notavelmente excluindo o ambiente $/ m \_$) e corresponde a várias vogais orais diferentes em Arikapú. Apesar da alta variabilidade de Arikapú em geral, talvez devido a sua situação prolongada de obsolescência, é possível observar que estas correspondências de sons não-idênticos ocorrem no ambiente de consoantes alveolares orais em Arikapú e consoantes alveolares orais ou nasais

\footnotetext{
13 Como sugerido por Denny Moore (c.p.).
}

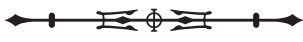


em Djeoromitxí. Nestas correspondências, provavelmente, havia desnasalização em Arikapú antigo e talvez anteriorização ${ }^{14}$. Além disso, /õ/em Djeoromitxí corresponde a várias vogais nasais em Arikapú. A correspondência ã:õ também ocorre nos mesmos ambientes de consoantes alveolares e está em distribuição complementar com a de õ:t. Uma hipótese possível é que /õ/ em Arikapú antigo foi preservado no ambiente $/ m_{\ldots}$. Em outros ambientes, a vogal em Arikapú perdeu a nasalidade e foi anteriorizada. Em alguns casos do ambiente $/ n_{\text {__ }}$, a vogal foi somente anteriorizada, sem perder nasalidade. Por enquanto, os dados mostram uma tendência geral, mas, infelizmente, não nos permitem entendimento mais profundo dos condicionamentos que deram origem às mudanças históricas envolvendo *õ. Em todos estes casos, o /õ/ em uma das línguas Jabutí foi reconstruído na proto-língua como $* \tilde{0}^{15}$.

Existem algumas outras correspondências de vogais nasais em Arikapú com /õ/ em Djeoromitxí. Na correspondência ũ:õ, Proto-Jabutí *ũ foi preservado em Arikapú, mas fundiu com /õ/ em Djeoromitxí, que não tem /ũ/. A correspondência u:õ provavelmente resultou de desnasalização em Arikapú16. Uma análise alternativa, na qual /ũ/ de Arikapú viria de *õ, implicaria no fato de Proto-Jabutí talvez não ter tido *ũ.

As tendências gerais que parecem dar origem às correspondências discutidas aqui são anteriorização em Djeoromitxí e centralização em Arikapú.

\section{As consoantes}

A Tabela 6 resume as correspondências fonêmicas consonantais entre Arikapú e Djeoromitxí, com a sua reconstrução em Proto-Jabutí.

Tabela 6. Correspondências consonantais e reconstruções.

(continua)

\begin{tabular}{|c|c|c|c|c|}
\hline PJab & Ari & Dje & Ambientes PJab & Número no Apêndice \\
\hline *h & $\mathbf{h}$ & h & /_E, ã, $\tilde{t}$ & $29,67,87,94,132,135,144,177,183,231,234,245,265$ \\
\hline *h & $\mathrm{t} \int, \varnothing$ & $\mathbf{h}$ & I_i,i & $42,112,150,178,179$ \\
\hline *k & $\mathbf{k}$ & $\mathbf{k}$ & I_a, $, \partial, u, o, \dot{t}, \tilde{u}$ & $\begin{array}{l}1,2,3,4,10,(11), 14,16,20,22,25,30,32,35,36,43,46,51,52,53,55,56,60, \\
70,73,74,76,77,109,112,118,119,126,133,136,138,140,141,(147), 148,160, \\
161,162,163,166,170,180,183,195,200,201,205,206,208,210,223,224,228, \\
229,(240), 241,242,243,246,251,259\end{array}$ \\
\hline * $\mathbf{m}$ & $\mathbf{m}[\mathbf{b}, \mathbf{m}]$ & $\mathbf{m}[\mathbf{b}, \mathbf{m}]$ & [quase todos] & $\begin{array}{l}2,10,37,40,44,46,47,48,50,59,64,66,72,73,89,97,108,120,126,128, \\
130,134,137,138,143,151,153,158,159,172,180,182,187,(194), 195,200,212, \\
225,235,240,241,255,265\end{array}$ \\
\hline * & $\mathbf{m}[\mathbf{b}]$ & bz & 1 & $5,8,9,134,136,149,150,206,208$ \\
\hline
\end{tabular}

\footnotetext{
${ }^{14}$ Mais especificamente, a correspondência o:õ ocorre quase sempre no ambiente de $/ r \_$e a:õ no ambiente de /t_ _. Neste ponto, não é possível explicar as exceções.

15 Não foram encontradas correspondências que permitem reconstrução da origem de Arikapú /õ/ no ambiente /n_.

${ }^{16}$ É ainda possivel que os cognatos (140) e (228) representem evidência para uma correspondência U:t. Com respeito à primeira, veja nota 23. A segunda, uka: $u k a$ ('espécie de sapo') não representa evidência forte, uma vez que estes cognatos parecem com Kwazá (isolado) ukato ('espécie de sapo') e podem ter sido formados numa base onomatopaica. Uma explicação muito especulativa em termos de Proto-Jabutí implicaria no fato de ambas as vogais terem sido desnasalizadas de $* \tilde{u}$.
}

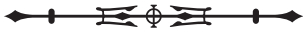


Tabela 6. Correspondências consonantais e reconstruções.

(conclusão)

\begin{tabular}{|c|c|c|c|c|}
\hline PJab & Ari & Dje & Ambientes PJab & Número no Apêndice \\
\hline *n & $\mathbf{n}[\mathbf{d}, \mathbf{n}]$ & $\mathbf{n}$ & I_ə, & $\begin{array}{l}1,18,22,24,30,31,39,43,49,56,75,91,114,118,121,145,154,160,161,173, \\
184,186,189,194,207,213,230,242,244,249,252,261\end{array}$ \\
\hline *n & $\mathbf{n}[\mathbf{d}, \mathbf{n}]$ & $\varnothing,(\mathbf{w})$ & I_E,ə,it & $131,161,226,(230)$ \\
\hline * p & $\mathbf{p}$ & $\mathbf{p}$ & [quase todos orais] & $\begin{array}{l}3,7,18,20,21,27,30,55,63,64,65,69,72,78,86,104,113,115,119,139,(147), \\
148,155,168,170,176,182,(184), 191,193,194,(201), 222,233,239,246,259, \\
262\end{array}$ \\
\hline 粠 & $\mathbf{t}$ & $\mathbf{t}$ & ${ }_{\perp} \varepsilon \varepsilon, \partial, \dot{i}, \dot{t}, \tilde{O}, \tilde{u}, \tilde{a}, \tilde{t}$ & $\begin{array}{l}17,29,37,50,63,81,87,91,93,94,100,106,118,123,142,145,153,158,175 \\
178,197,199,223,234,237,244,(247), 248,251,253\end{array}$ \\
\hline *t $\int$ & tS & t & $/ \quad i, \tilde{l}, \varepsilon$ & $15,48,51,92,124,146,148,168,176,253,257$ \\
\hline *t $\int$ & $t \int, h$ & $\mathbf{h}$ & I\#_a,u & $8,19,25,27,44,45,74,89,111,121,130,135,141,142,152,238$ \\
\hline *t $\int$ & $\mathrm{t} \int, \varnothing$ & $\mathbf{r}$ & $N_{-} a, u$ & $\begin{array}{l}19,25,27,31,36,37,44,45,74,85,89,92,96,111,115,121,141,152,162,176 \\
186,214,236,254\end{array}$ \\
\hline *t $\int$ & $\mathbf{k}$ & t5 & I_o & $67,113,144,197,216,218$ \\
\hline *d3 & t & d3 & 1 & 7, 40, 95, 105, 125, (129), 243 \\
\hline *d3 & $\mathbf{t}, \varnothing$ & d3 & 1 & 185,222 \\
\hline * r & $\mathbf{r}$ & $\mathbf{r}, \mathbf{h}$ & ${ }_{\perp} \varepsilon, \partial, i, \dot{i}, O, \tilde{O}, \tilde{t}$ & $\begin{array}{l}(11), 16,39,42,54,60,68,76,79,81,83,(84), 119,122,137,149,151,205,212 \text {, } \\
219,229,235,238,255,260,261,265\end{array}$ \\
\hline * r & $\mathbf{r}$ & $\mathbf{n}$ & /_ Ĩ,õ, ũ, ã & $13,43,165,206,249,256,257,258$ \\
\hline *r & $\mathbf{r}$ & $\varnothing$ & /C_a,i,õ,ã & $\begin{array}{l}\begin{array}{l}10,18,20,21,40,64,65,66,86,95,96,110,128,143,148,158,191,192,233, \\
246,254\end{array}\end{array}$ \\
\hline
\end{tabular}

Algumas consoantes se mostram estáveis, como $h: h, k: k, m: m, n: n, p: p, t: t$, de que há bastante exemplos, incluindo os da lista básica de Swadesh.

$\bigcirc$ *t ocorre somente antes de vogais não-centrais orais (exceto em *patfi 'mosquito' (168), que pode ter uma origem simbólica). A correspondência t: :t $\int$ ocorre somente no ambiente de vogais anteriores, /_ i,ĩ, $\varepsilon$, mas está em contraste com uma correspondência de sons não-idênticos $t \int: d 3$, que ocorre somente no ambiente de $/ \ldots i^{17}$. Por isso se reconstrói $* t \int e^{*} d z$, respectivamente ${ }^{18}$. Nos outros ambientes, as correspondências $t \int: h$ e $t \int: r$ sugerem que $* t \int$ foi preservado em Arikapú, mas não em Djeoromitxí. Foi ilustrado na seção Características básicas da língua Djeoromitxí como certas raízes lexicais de Djeoromitxí mostram alternância morfofonológica entre /r/ (ocorrendo dentro da palavra) e /h/ (no início da palavra). Provavelmente *t mudou para /r/ em Djeoromitxí, em que depois /r/mudou para /h/ no início da palavra e foi preservado como /t J/ em Arikapú em todas as posições (nos casos 19, 25, 27, 44, 45, 74, 89, 111, 141, 152). Em um número de casos da correspondência $t: r, h$ a alternância não foi observada nos dados disponíveis, mas a distribuição de /r/ e /h/ nas palavras Djeoromitxí ainda reflete esta alternância.

\footnotetext{
17 A única exceção é ARI tJui, DJE dzui 'inambu relógio' (129), que pode representar uma onomatopéia. A forma DJE murikarł 'cará moela' possivelmente se deve à vogal * I que ainda existe em Arikapú, mas que fundiu com /i/em Djeoromitxí. No entanto, o equivalente em Arikapú não foi registrado com a vogal /I/, mas com /i/: mutfika.

18 Djeoromitxí /dz/ se encontra também em outros ambientes, mas entre estas palavras não foram atestados cognatos em Arikapú.
}

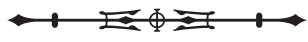


Como mencionado em Características básicas da língua Arikapú, existe um pequeno número de lexemas em Arikapú em que /tJ/ alterna idiossincraticamente com / $h$ / e com ausência de /t $\int /$. Além disso, as correspondências $t \int, h$ :

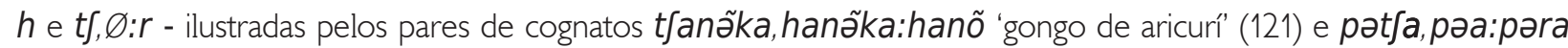
'formar, colocar, tecer, encostar' (115) - sugerem a existência de uma conexão histórica com a alternância / $r \sim h /$ em Djeoromitxí. As consoantes envolvidas nestas alternâncias são provavelmente reflexos de $* t$. Considero também que os pares patfiu:patfiru 'noite' (176) e kuamrəj:kurami 'urucum' (254) contêm reflexos de *tf.

Por outro lado, a correspondência t $\int$, $\varnothing: h$ - ilustrada pelo par de cognatos kui,kutfi:kuhi 'fluir, derramar, correr, jogar' (112) - envolve a posição de / $h$ / dentro da palavra em Djeoromitxí, seguido pela vogal anterior fechada /i/, enquanto a segunda variante da forma Arikapú ocorre somente sob negação ${ }^{19}$. Tudo isso sugere que talvez não se trate de reflexos da consoante $* t \int$ neste par, mas de uma das consoantes *h, *k ou *t, cujos reflexos idênticos em pares de cognatos não foram atestados no ambiente de / _ i. Sabendo também que em Arikapú o/h/não ocorre no ambiente de /_ i, o candidato mais provável parece *h. Em analogia, as poucas outras correspondências de tf: $h$ no ambiente / _ i,i devem também ser consideradas como reflexos (não-idênticos) de *h.

Há ainda dois casos de correspondência $t \int, \varnothing: d z$ que se poderia considerar como reflexo de $* d z$, em vista do ambiente idêntico com o de t:: $d z$ e também da opcionalidade relativa da correspondência $t \int \sim \varnothing$ em Arikapú.

A correspondência $k: t \int$ é considerada como reflexo de *t p porque ocorre somente no ambiente da vogal central *ə. Na nota 12, seção As vogais, foi explicado como esta reconstrução ocorre simultaneamente com a reconstrução da correspondência ə: $\varepsilon$ e, conseqüentemente, como nos poucos cognatos que mostram esta correspondência houve uma combinação de duas mudanças diacrônicas ${ }^{20}$.

Não obstante a análise de Pires (1992), suponho, como foi explicado acima, que o Djeoromitxí é similar ao Arikapú no que tange à ausência de contraste fonêmico entre as consoantes nasais $[\mathrm{m}] \mathrm{e}[\mathrm{n}]$ e as oclusivas sonoras $[\mathrm{b}] \mathrm{e}[\mathrm{d}]$. Estes sons são considerados como alofones dos fonemas consonantais nasais $/ \mathrm{m} / \mathrm{e} / \mathrm{n} /$. Optei por analisar o sistema da proto-língua também desta forma ${ }^{21}$, o que não implica em Arikapú e Djeoromitxí sempre empregarem os mesmos alofones em pares de cognatos.

$\mathrm{Na}$ análise de Pires (1992, p. 20), o /bz/ representa um fonema raro em Djeoromitxí, que ocorre somente antes do /i/, embora contraste com /m/. Em cognatos de Arikapú não existe este contraste, mas existe um contraste entre /i/e /I/ no mesmo ambiente. Eduardo Ribeiro (c.p.) aponta a probabilidade de que o [bz] como alofone de /m/ numa fase antiga de Djeoromitxí, condicionado por um /i/ seguinte, adquiriu status fonêmico /bz/, quando a língua perdeu o contraste entre /i/ e /I/, contraste que foi preservado em Arikapú. Há somente pouquíssimos cognatos completos ${ }^{22}$.

19 Este verbo possivelmente vem de uma forma que inclui um prefixo lexicalizado, cuja função original ainda não foi identificada. Um prefixo similar se encontra também em DJE kuhi 'jogar, perder' vs. hi 'jogar, botar'.

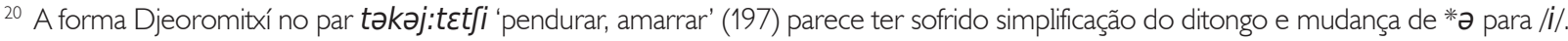

${ }^{21}$ Como dito antes, o sistema fonológico provavelmente poderia ser analisado com igual razão como tendo consoantes oclusivas sonoras /b/e /d/, em lugar de consoantes nasais / $\mathrm{m} /$ e $/ \mathrm{n} /$. Sistemas (parcialmente) similares foram atestados em línguas da família Tuparí, como Makurap e Mekens (Moore; Galucio, 1994), além de um número de línguas Jê (Rodrigues, 1999).

22 Vários cognatos prováveis não são reconstruíveis porque correspondem somente parcialmente, como ARI mio e DJE bzia 'companheiro, dono' e ARI hətã e DJE bzitã 'todo' (247). A reconstrução de certos cognatos talvez não deva ser usada como comprovante de relação genética porque representam formas regionais, como ARI mirə e DJE bzire 'macaco prego' (149), que são muito similares com Kwazá (isolado) hiri e Kanoê (isolado) iri 'macaco prego' (van der Voort, 2005) e Wayurú (Tuparí) [berø] 'macaco prego'. Um outro exemplo é ARI miaku e DJE bzicku [bzع'ku] 'jabuti' (136), que provavelmente representa um empréstimo do Makuráp (família Tuparí) biaku 'jabutí'. Mesmo assim, estas formas podem ser emprestadas já na proto-língua e, conseqüentemente, podem ser reconstruíveis e confirmar as correspondências estabelecidas.

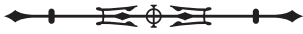


Em alguns casos, aparentemente, $\mathrm{o}$ *n desapareceu ou foi substituído por um glide em Djeoromitxí, em ambientes onde foi preservado em Arikapú.

A correspondência $r: r, h$ tem exceção no início das palavras em Djeoromitxí, em que / $r$ / sofre a mesma flutuação fonêmica com /h/ que ocorre na correspondência $t \int: r, h^{23,24}$. A correspondência $r: n$ mostra que em Djeoromitxí houve uma divisão do Proto-Jabutí * $r$ : antes de vogais orais o [ $r$ ] permaneceu $/ r / e$ antes de vogais nasais virou [ $n]$ e fundiu com $/ n /$ em Djeoromit $21^{25}$.

As correspondências mr:m, pr:p, kr:t mostram que há combinações de consoantes no início da sílaba, onde/r/ está na segunda posição em Arikapú. Isto não ocorre em Djeoromitxí, mas, assumindo que houve simplificação nesta língua, combinações de consoantes podem ser reconstruídas em Proto-Jabutî́2. Não está claro se (68), (235) e (265) contêm combinações de consoantes que foram simplificadas em Djeoromitxí pela inserção de uma vogal, ou se havia uma vogal na proto-língua que foi omitida em Arikapú. A correspondência kr:t é bastante rara ${ }^{27}$ e, se também neste caso uma combinação de consoantes foi simplificada, indica que poderia ter uma correspondência $k: t$. No entanto, não existe evidência para isto.

\section{Os glides}

A Tabela 7 resume as correspondências fonêmicas semi-consonantais (e talvez semi-vocálicas) entre Arikapú e Djeoromitxí, com a sua reconstrução em Proto-Jabutí.

Tabela 7. Correspondências de glides e reconstruções.

\begin{tabular}{|c|c|c|c|c|}
\hline PJab & Ari & Dje & Ambientes PJab & Número no Apêndice \\
\hline *j & $\mathbf{j}$ & $\varnothing$ & $/ a, \varepsilon, \partial, i, u, \dot{t}, \tilde{a}, \tilde{o}, \tilde{t}$ & $\begin{array}{l}8,10,(11), 18,29,30,37,40,50,65,66,67,84,94,96,100,110,118,119,128, \\
(140), 142,148,172,186,191,193,197,244,245,246,254,256,257,262\end{array}$ \\
\hline 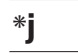 & j & $\mathbf{i}$ & $/ \varepsilon$ & $(87), 134$ \\
\hline *w & $\mathbf{w}$ & $\mathbf{w}$ & $I \ldots, \varepsilon, i, I$ & $41,80,94,109,111,132,205,209$ \\
\hline$* \mathbf{w}$ & $\mathbf{w}$ & $\mathbf{u}, \varnothing$ & $/ a, o ̂$ & $35,237,251$ \\
\hline
\end{tabular}

Algumas correspondências sugerem que Proto-Jabutí possui glides. $\bigcirc$ *j geralmente funciona como semivogal em ditongos decrescentes. Pires (1992, p. 42-44) nota que em Djeoromitxí não existem ditongos no nível fonológico ${ }^{28}$.

${ }^{23}$ Não há clareza sobre o par kuraj:kuhi 'jogar, perder, cair, derramar' (140) onde DJE [h] ocorre dentro da palavra. É possível que o ambiente /_ i faça parte da explicação, como na correspondência t $\int, \varnothing: h$. Entre os casos especiais daquela correspondência está um verbo que provavelmente é etimologicamente relacionado: kui,kutfi:kuhi 'fluir, derramar, correr, jogar' (112). Veja também nota 19.

${ }^{24}$ Se os elementos posposicionais são considerados como palavras independentes, a consoante do elemento dativo ri (83) em Djeoromitxí, ocorrendo no início da palavra, não pode ser um reflexo de *r.

${ }^{25}$ Foi atestado somente um caso em DJE com [r] antecedendo vogal nasal: o verbo mĩrĩ 'colar' (ARI mrz̃to) (68).

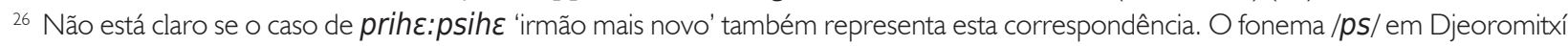
ocorre somente antes de /i/, similar ao /bz/ discutido acima, mas os dados do Arikapú não mostram traços do contraste entre /i/ e /I/ em relação ao /ps/.

${ }^{27}$ Quatro dos cinco pares atestados são etimologicamente estreitamente relacionados. Existem outras formas que correspondem, porém somente parcialmente: krakra:kata 'cabelo branco (de uma pessoa idosa)'.

${ }^{28}$ Em poucos casos o [j] foi preservado em Arikapú tanto quanto em Djeoromitxí, mas os cognatos correspondem somente parcialmente ou vêm de empréstimos possíveis: *hãt.j, ARI hãtãj, DJE hõtoi 'devagar' (87), e *mejmia, ARI mejmia, DJE meibzia 'irara, papa-mel' (134).

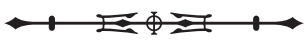


Alguns exemplos sugerem que o *j foi preservado somente em Arikapú, enquanto desapareceu em Djeoromitxí. Em um número de casos (8, 10, 18, 37, 40, 50, 66, 84, 118, 119, 140, 186, 193, 197, 244, 254), o ambiente do glide final em Proto-Jabutí, / j\#, pode ter causado mudança da vogal precedente em Djeoromitxí (veja As vogais).

Não se pode excluir a possibilidade de que em alguns cognatos talvez houvesse tido inserção (opcional) de /j/ em Arikapú (veja seção Características básicas da língua Arikapú). Porém, isto não é provável nos casos onde a seqüência *V+*j resultou em uma vogal anterior em Djeoromitxí. Isso pode ser uma explicação da falta de nasalidade na vogal

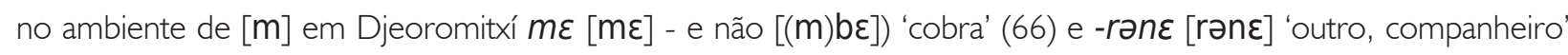
(186). Em ambas correspondências envolvendo reflexos de *j houve simplificação da sílaba em Djeoromitxí. Em outros casos, a nasalização foi preservada em Djeoromitxí, como testemunhado pela forma Djeoromitxí [mẽdzi] 'calango' (40) (que é etimologicamente relacionada com 'cobra') e [tanz̃] timbó (244).

O glide * $w$ geralmente funciona como semi-consoante. É possível ter havido inserção de / $w /$ em Djeoromitxí em (45). Existem poucos exemplos de *w usado como semivogal. Neste caso, Djeoromitxí simplificou-se ou ficou com um alofone de /U/. Outros fenômenos em cognatos prováveis que envolvem /W/ em Arikapú ou Djeoromitxí não são resolúveis nesta fase de pesquisa.

\section{Resumo do sistema fonológico do Proto-Jabutí}

Os fonemas reconstruídos para o Proto-Jabutí são expostos na Tabela 8.

Tabela 8. Fonemas Proto-Jabutí.

\begin{tabular}{|c|c|c|c|c|c|c|c|c|c|}
\hline \multicolumn{6}{|c|}{ Vogais } & \multirow{2}{*}{\multicolumn{4}{|c|}{ Consoantes }} \\
\hline \multicolumn{3}{|c|}{ Orais } & \multicolumn{3}{|c|}{ Nasais } & & & & \\
\hline$i$ & $\dot{t}$ & $u$ & $\tilde{\imath}$ & $\tilde{t}$ & $\tilde{u}$ & $p$ & $t$ & ts & k \\
\hline I & $\partial$ & & & & & $m$ & $n$ & $d 3$ & \\
\hline$\varepsilon$ & & 0 & $\tilde{\varepsilon}$ & & $\tilde{o}$ & & $r$ & & \\
\hline & $a$ & & & $\tilde{a}$ & & w & & $j$ & $h$ \\
\hline
\end{tabular}

Além dos cognatos listados no Apêndice, existem ainda cognatos prováveis, dos quais muitos não foram incluídos. Trata-se de pares de raízes em Arikapú e Djeoromitxí que correspondem parcialmente, mas que incluem fonemas que não batem com os padrões atestados amplamente (como foi ilustrado nas notas 22 e 28). Esses pares dão uma forte impressão de serem cognatos, embora as relações exatas entre eles ainda não tenham sido entendidas. É também possível que certas fronteiras morfêmicas, que poderiam condicionar mudanças fonológicas, não tenham sido identificadas. Além disso, é possível que certas formas venham de empréstimos entre as duas línguas, o que produziria correspondências diferentes daquelas entre cognatos verdadeiros. Finalmente, é possível que haja erros na transcrição ou que, em vista da alta variação na produção de certas formas de Arikapú, estas tenham sido atingidas por efeitos de obsolescência.

Um número considerável de raízes lexicais das línguas Jabutí é cognato com raízes nas línguas Jê.

\section{MORFOSSINTAXE}

As seções Características básicas da língua Arikapú e Características da língua Djeoromitxí mostram que as gramáticas de Arikapú e Djeoromitxí são bastante similares. Provavelmente, muitos traços similares representam características

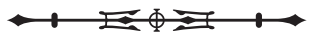


da língua ancestral, especialmente se as partículas e as formas presas gramaticais são cognatas. Nesta seção, discuto estes traços e formas comuns.

Os sistemas de marcação de pessoa das línguas Jabutí são similares, tanto na forma quanto no comportamento. É provável que Proto-Jabutí também fosse uma língua ergativa. A homofonia das formas para primeira e terceira pessoas do singular foi preservada em Arikapú, enquanto Djeoromitxí optou pela expressão 'zero' da primeira pessoa $^{29}$ (Tabela 9).

Tabela 9. Prefixos pessoais.

\begin{tabular}{cccc}
\hline Pessoa & Proto-Jabutí & Arikapú & Djeoromitxí \\
\hline 1 & $* i$ & $i$ & $\varnothing$ \\
2 & $* a$ & $a$ & $a$ \\
3 & $* i$ & $i, \varnothing$ & $i$ \\
1PL & $* h i$ & $t f i$ & $h i$ \\
\hline
\end{tabular}

○ uso não-específico da primeira pessoa do plural também representa um traço comum, embora haja ainda a possibilidade de uma explicação universalista para isto, porque é atestado em muitas línguas do mundo, incluindo línguas indígenas de Rondônia, como Gavião.

Um outro traço comum é o uso de elementos posposicionais (que podem ser considerados como sufixos em Arikapú e clíticos em Djeoromitxí) com formas e sentidos similares (Tabela 10).

Tabela 10. Elementos posposicionais.

\begin{tabular}{|c|c|c|c|}
\hline função & Proto-Jabutí & Arikapú & Djeoromitxí \\
\hline ablativo & *kunĩ & -kunĩ & kuni \\
\hline beneficiário & $(* \varepsilon n \tilde{t})$ & $-n \tilde{\varepsilon}$ & $\varepsilon n i$ \\
\hline comitativo & *pakəj & -pakəj & pakə \\
\hline dativo & $* r i$ & $-r i$ & ri \\
\hline instrumental & *nə & $-n ә$ & $\partial$ \\
\hline locativo & $* t \int \varepsilon$ & $-t \int \varepsilon$ & $t \int \varepsilon$ \\
\hline
\end{tabular}

Como visto em Características básicas da língua Arikapú e Características da língua Djeoromitxí, nem todas posposições são compartilhadas, como o Djeoromitxí agentivo $m \varepsilon$, o Djeoromitxí dativo ma, o Arikapú aversivo -rij e o Arikapú similativo -rã.

Dos outros elementos discutidos, alguns são reconstruíveis na proto-língua (Tabela 11).

29 Esta homofonia causa ambigüidade em Arikapú entre uma interpretação de primeira pessoa e de terceira pessoa não-específica, por exemplo, i-t Jawa 'flor dele', 'minha flor'. Uma homofonia muito similar foi atestada em várias línguas da família Jê, como Xerente (Ribeiro, c.p.). Também neste sentido, Arikapú parece mais conservador do que Djeoromitxí.

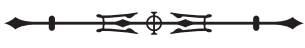


Tabela 11. Outros morfemas gramaticais.

\begin{tabular}{|c|c|c|c|}
\hline função & Proto-Jabutí & Arikapú & Djeoromitxí \\
\hline negativo & *tõ & $t \tilde{}$ & tõ \\
\hline intensificador & *-wehE & -wehE & $-w \varepsilon h \varepsilon$ \\
\hline aumentativo & $*$-t $\int i t \int i$ & $-t \int i t \int i$ & $-t \int i t \int i$ \\
\hline
\end{tabular}

Mesmo assim, um número maior de morfemas gramaticais não permite uma reconstrução neste momento. Isto se deve parcialmente à falta de dados em uma das línguas Jabutí, como o imperativo negativo -pł em Arikapú, ou o interrogativo hi e passado $t \int \varepsilon$ em Djeoromitxí. Além disso, há morfemas que são muito diferentes com respeito à sua forma, como Arikapú futuro -wiro e Djeoromitxí futuro ma. Finalmente, as línguas podem ter se influenciado mutuamente ou podem ter sofrido influência das línguas vizinhas, por exemplo, o nominalizador perfectivo de Arikapú, hã ([hã] ou [hã]), e o nominalizador adjetival de Djeoromitxí, hə, não se reconstroem na proto-língua por causa de falta de correspondência sistemática da vogal. O elemento não é muito produtivo em Arikapú e seu uso às vezes parece um calque no Djeoromitxí ${ }^{30}$.

Não está claro se Proto-Jabutí possui classificadores nominais. Como visto em Características básicas da língua Arikapú e Características da língua Djeoromitxí, as línguas Jabutí parecem ter uma categoria limitada de elementos classificadores. Alguns são reconstruíveis (Tabela 12).

Tabela 12. Classificadores.

\begin{tabular}{|c|c|c|c|}
\hline semente, caroço & *-hã & -hã & $-h o ̃$ \\
\hline redondo & $*-k a$ & $-k a$ & $-k a$ \\
\hline couro, casca & *kə & kə & kə \\
\hline casca & *-kakə & $-k a k ə$ & $-k a k \partial$ \\
\hline buraco & $*-k o$ & $-k o$ & $-k t$ \\
\hline carne & *-nĩ & $-n \tilde{~}$ & $-n i ̃$ \\
\hline espinho & *-nĩ & $-n i ̃$ & $-n i ̃$ \\
\hline pamonha, comida & *nũ & nũ & nõ \\
\hline verme & *-re & $-r \varepsilon$ & $-r \varepsilon$ \\
\hline $\mathrm{ovo}^{31}$ & & $-r \tilde{\varepsilon}$ & $-d z \varepsilon$ \\
\hline
\end{tabular}

Alguns elementos classificadores resistem à reconstrução, como Arikapú -mrẽ,. Djeoromitxí -mã 'bagaço' e Arikapú -mrə, Djeoromitxí -tu 'pó'. Alguns dos classificadores parecem fossilizados em substantivos como 'boca' e 'língua' (respectivamente 25 e 145 no Apêndice). $O$ elemento -kakə 'casca de noz, semente ou besouro' parece uma composição de dois elementos. Uma possibilidade é os classificadores terem sido derivados de substantivos compostos, como sugerido para Djeoromitxí por Pires (1992, p. 58-59). Por outro lado, os classificadores geralmente não ocorrem livres, mas com um marcador de pessoa precedente, como irع 'gongo dele' em Arikapú e Djeoromitxí,

\footnotetext{
30 Além disso, a forma é visivelmente similar ao nominalizador -hã de Kwaza (isolada), o que talvez não seja uma coincidência.

${ }^{31}$ Esta raiz não é reconstruível em Proto-Jabutí, mas em Proto-Jê sim, veja nota 61.
}

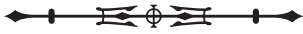


ou como segunda parte em um composto. É possível, ainda, que os classificadores representem uma fase intermediária no processo de gramaticalização. Com exceção de *-ka 'redondo', *-kakə 'casca' e *-rع 'verme', todos os elementos na lista acima são reconstruíveis em Proto-Jê (Ribeiro, c.p.).

Foi mostrado em van der Voort (2005) que várias línguas genealogicamente não relacionadas, como as línguas Nambikwara, Tacana e isoladas de Rondônia, mostram sistemas classificadores similares. Algumas línguas têm até formas similares e é notável que várias formas não reconstruíveis nas línguas Jabutí se parecem com formas de outras línguas da região, como o Kwazá (isolado) -mẼ 'mingau'. Com respeito à reconstrução do classificador *-nĩ 'espinho, folha' e *nũ 'pamonha, mingau, comida' de Proto-Jabutí, pode-se concluir que talvez seja melhor não utilizá-los como comprovante de relação genética, uma vez que são idênticos com Kwazá -nĩ 'espinho, agulha' e também em várias outras línguas, -nũ 'pamonha, farinha'. Por outro lado, estas formas também podem ter se espalhado do Proto-Jabutí para as outras línguas.

Finalmente, vale a observação de que as características sintáticas compartilhadas pelas línguas Jabutí provavelmente existiam na proto-língua. A ordem básica das palavras na frase verbal parece ter sido OV, a posição do $\mathrm{S}$ tendo maior liberdade. Em ambas as línguas há evidência de que o objeto e o verbo juntos formam um único constituinte sintático, o que então deve ter sido uma das características sintáticas do Proto-Jabutí.

\section{CONCLUSÕES}

As línguas Arikapú e Djeoromitxí são obviamente línguas estreitamente relacionadas. Os povos Arikapú e Djeoromitxí se consideram tribos irmãs, podendo ser tratados coletivamente como os povos Jabutí.

Para Arikapú, a complexidade fonológica reside mais no quadro vocálico e para Djeoromitxí mais no quadro consonantal.

Em geral a língua Arikapú parece ser a mais conservadora, enquanto a língua Djeoromitxí é a mais avançada em termos de mudanças fonéticas e fonológicas. A ausência (perda) de [j] em muitos casos em Djeoromitxí sugere este fato, como também a fusão de * I e *i. Além disso, a simplificação de combinações de consoantes e de vogais resultou em bastante homofonia ${ }^{32}$.

As línguas Jabutí mostram certas semelhanças lexicais e gramaticais com outras línguas da região, com as quais não estão relacionadas geneticamente, o que indica difusão areal. Não obstante a possibilidade das línguas (Proto-) Jabutí terem chegado à região mais recentemente que outras (famílias de) línguas, não é impossível que estas línguas (Proto-) Jabutí tenham desencadeado certas difusões, como os classificadores como -nũ 'mingau' e -nĩ 'espinho'.

Este artigo representa a primeira tentativa de tratar das relações históricas das línguas Jabutí. De fato, o artigo representa um dos pouquíssimos trabalhos publicados sobre as línguas Jabutí em qualquer área. Ainda está faltando a publicação de trabalhos descritivos mais abrangentes de Arikapú e Djeoromitxí. Por isso, o presente artigo é somente o primeiro passo e, antecipando as avaliações críticas pelo leitor, enquanto o trabalho descritivo avança também, esperase que as análises apresentadas aqui sejam revisadas e melhoradas no futuro.

\footnotetext{
32 Também não posso excluir a possibilidade da impressão de Arikapú ser mais conservador ter sido reforçada por uma tendência em favor de Arikapú, cuja descrição foi o alvo do meu trabalho de campo, e por uma relativa escassez de dados de Djeoromitxí.
}

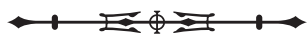




\section{AGRADECIMENTOS}

Gostaria de agradecer às comunidades indígenas das reservas Rio Branco e Rio Guaporé, pela sua hospitalidade generosa. Em especial, devo muito à minha professora, Sra. Nazaré Arikapú; ao Sr. Mamoa Arikapú e aos Srs. Raimundo Jabutí, André, Armando, José Roberto Jabutí e José Purinté Arikapú, por terem me ensinado sobre sua língua e cultura. À Fundação Neerlandesa para o Avanço da Pesquisa Tropical (WOTRO, estipêndio nr. W39-273), por ter financiado de forma generosa todo o projeto Arikapú. Ademais, gostaria de agradecer a Eduardo Ribeiro, pelo intercâmbio imprescindível na pesquisa histórico-comparativa das línguas Jabutí. Também a Gale Goodwin Gómez e Gessiane Picanço, pelos seus comentários; Sérgio Meira, pelo ensino inicial de reconstrução histórica; Sebastian Drude e Denny Moore, pelas suas inúmeras observações profundas e estimulantes. Finalmente, estou devendo muito a Vilacy Galúcio e aos (às) pareceristas anônimos, cujos comentários foram essenciais na finalização deste artigo. Porém, estas pessoas não necessariamente concordam com todas as asserções levantadas neste artigo e a responsabilidade pelo conteúdo permanece inteiramente minha.

\section{REFERÊNCIAS}

BACELAR, Laércio Nora. Gramática da língua Kanoê, 2004. Tese (Doutorado) - Katholieke Universiteit Nijmegen, Nijmegen, 2004.

BYNON, Theodora. Historical linguistics. Cambridge: Cambridge University Press,1983 [1977].

CAMPBELL, Lyle. Historical linguistics: an introduction. Edinburgh: Edinburgh University Press, 1998.

CASPAR, Franz. Die Tuparí: ein Indianerstamm in Westbrasilien, Monographien zur Völkerkunde herausgegeben vom Hamburgischen Museum für Völkerkunde, VII, Berlin / New York: Walter de Gruyter, 1975.

CASPAR, Franz. Tuparí: entre os índios, nas florestas brasileiras. São Paulo: Melhoramentos, 1958.

CASPAR, Franz. A expedição de P. H. Fawcett à tribo dos Maxubi em 1914. In: CONGRESSO INTERNACIONAL DE AMERICANISTAS, 31, São Paulo, 1955. Anais... São Paulo, 1955. p. 113-120.

FAWCETT, Percy Harrison. Exploration Fawcett. London: Hutchinson, 1953. (apresentação: Brian Fawcett).

FAWCETT, Percy Harrison. Bolivian Exploration, 1913-1914. Geographical Journal, London, v. 45, p. 219-228, 1915. (com 7 fotos e 1 mapa após p. 272).

GREENBERG, Joseph. Language in the Americas. Stanford: Stanford University Press, 1987.

HOCK, Hans Henrich. Principles of historical linguistics. Berlin / New York: Mouton de Gruyter, 1991 [1986].

JEFFERS, Robert J.; LEHISTE, Ilse. Principles and methods for historical linguistics. Cambridge / London: The MIT Press, 1992 [1979].

MALDI, Denise. O Complexo cultural do marico: sociedades indígenas dos rios Branco, Colorado e Mequens, afluentes do médio Guaporé. Boletim do Museu Paraense Emílio Goeldi, série Antropologia, Belém, v. 7, n. 2, p. 209-269, 1991.

MINDLIN, Betty; NARRADORES INDÍGENAS. Terra grávida. Rio de Janeiro: Rosa dos Tempos, 1999.

MINDLIN, Betty; NARRADORES INDÍGENAS. Moqueca de maridos: mitos eróticos, 2. ed. Rio de Janeiro: Rosa dos Tempos, 1998 [1997].

MOORE, Denny. Glossário Tuparí-Jaboti-Arikapú. Porto Velho, 1988. (manuscrito não-publicado, 4 p. 77 entradas Arikapú gravado de uma mulher bilíngüe Djeoromitxí-Arikapú em julho de 1988. No arquivo do Museu Goeldi, Belém).

MOORE, Denny; GALUCIO, Ana Vilacy. Reconstruction of Proto-Tupari consonants and vowels. In: LANGDON, Margaret (Org.). Survey of California and other Indian languages: Report 8. Columbus: Ohio State University, 1994. p. 119-130.

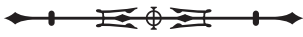


NIMUENDAJú, Curt. Cartas do sertão de Curt Nimuendajú para Carlos Estevão de Oliveira, Lisboa: Museu Nacional de Etnologia; Assírio \& Alvim, 2000. (apresentação e notas: Thekla Hartmann).

PIRES, Nádia Nascimento. Estudo da gramática da língua Jeoromitxí (Jabutí): aspectos sintáticos das cláusulas matrizes. 1992.157 f. Dissertação de Mestrado - Universidade de Campinas, Campinas, 1992.

PIRES, Nádia Nascimento; JABUTÍ, José Roberto; JABUTÍ, Vandete. Livro de escrita em Djeoromitxí (Jabutí). Belém: Museu Paraense Emílio Goeldi, 1995.

PIRES, Nádia Nascimento; JABUTÍ, José Roberto; JABUTÍ, Vandete. Livro de alfabetização em Djeoromitxí (Jabutí). Belém: Museu Paraense Emílio Goeldi, 1994.

RIBEIRO, Eduardo Rivail; VOORT, Hein van der. A inclusão das línguas Jabutí de Rondônia no tronco Macro-Jê. Recife, 2005. (manuscrito apresentado no IV Encontro Internacional sobre Línguas e Culturas Macro-Jê, 3-5 de novembro de 2005, Recife).

RIBEIRO, Eduardo Rivail; VOORT, Hein van der. Nimuendajú was right: the inclusion of the Jabuti language family in the Macro-Jê stock. International Journal of American Linguistics. (no prelo).

RIVET, Paul. La langue Mašubi. Journal de la Société des Américanistes, Paris, Nouvelle série, n. 42, p. 119-125, 1953.

RODRIGUES, Aryon Dall'Igna. Macro-Jê. In: DIXON, Robert M. W.; AIKHENVALD, Alexandra Y. (Orgs.). The Amazonian languages Cambridge: Cambridge University Press, 1999. p. 165-206. (Cambridge Language Surveys).

RODRIGUES, Aryon Dall'Igna. Línguas brasileiras: para o conhecimento das línguas indígenas. São Paulo: Loyola, 1986.

SEKELJ, Tibor. Donde la civilización termina: vida de las tribus del Amazonas. Buenos Aires: Albatros, 1950.

SEKI, Lucy. Gramática do Kamaiurá: língua Tupi-Guarani do Alto Xingu. Campinas: UNICAMP, 2000.

SNETHLAGE, Emil Heinrich. Musikinstrumente der Indianer des Guaporégebietes, Baessler-Archiv. Berlin: Dietrich Reimer / Andrews \& Steiner, 1939. (Beiträge zur Völkerkunde, n. 10).

SNETHLAGE, Emil Heinrich. Atiko Y: meine Erlebnisse bei den Indianern des Guaporé. Berlin: Klinkhardt \& Biermann Verlag, 1937.

VOORT, Hein van der. Os Jabuti. In: Povos Indígenas, Lista de povos. São Paulo: Instituto Socioambiental, 2006. Disponível em: < http:// www.socioambiental.org/pib/epi/jabuti/jabuti.shtm >. Acesso em: 07 nov. 2007.

VOORT, Hein van der. Kwaza in a comparative perspective. International Journal of American Linguistics, Chicago, v. 71, n. 4, p. 365-412, 2005

Recebido: 21/04/2007

Aprovado: 17/07/2007

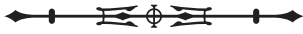




\section{APÊNDICE. Comparação lexical das línguas jabutí com reconstruções Proto-Jabutí.}

A lista comparativa de palavras neste Apêndice contém formas lexicais reconstruídas e numeradas, ilustrando os fonemas da proto-língua discutidos na seção $\bigcirc$ léxico e o sistema fonológico. Independente de terem sido reconstruídas ou não, esta lista inclui o vocabulário das 100 palavras básicas de Swadesh, como representado em Bynon (1983, p. 268), cuja numeração foi preservada como "s.número". Assim, para alguns pares listados neste Apêndice, todos referindo-se a palavras da lista básica de Swadesh, não apresentamos a forma reconstruída. As formas de Arikapú e Djeoromitxí foram colecionadas no campo por Hein van der Voort. As formas do Proto-Jabutí foram reconstruídas com a ajuda de Eduardo Ribeiro. Formas cuja reconstrução é questionável por serem onomatopaicas ou empréstimos possíveis, estão entre parênteses, assim como também é apresentado entre parênteses material extra encontrado apenas em uma das línguas, o que torna difícil decidir se existia na proto-forma ou não. Fonemas cuja reconstrução (ainda) não foi possível, estão representados por pontos (*.).

\begin{tabular}{|c|c|c|c|c|}
\hline NR & Português & Proto-Jabutí & Arikapú & Djeoromitxí \\
\hline 1 & $A B L$, vir de lá & *kunĩ & kunĩ & kuni \\
\hline 2 & açúcar, cana & $* m \varepsilon k \dot{t}$ & $m \varepsilon k i$ & mekidziji3 \\
\hline 3 & adicionar, сомIт & *pakə & pakə & pakə \\
\hline 4 & afastar & *koki & koki & $k \forall k i$ \\
\hline $5(s 75)$ & água, líquido & *miru & $m i$ & bziru \\
\hline $6(s 75 a)$ & água, líquido & $(* t)^{34}$ & $\dot{t}$ & $i$ \\
\hline 7 & agulha & *pudzi & put $\int i$ & pudzi \\
\hline 8 & algodão & *tJamuj & tfamuj & habzij \\
\hline $9(\mathrm{~s} 89)$ & amarelo 36 & *numuj & numu & bzinu \\
\hline 10 & amendoim & *kumrẽj & kumrəj & 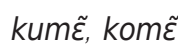 \\
\hline $11(s 65)$ & andar & $(* k \partial r \varepsilon j)^{37}$ & kərəj & dzekire \\
\hline $12(s 78)$ & areia & & kikira & nomart \\
\hline 13 & aricuri, palha, côco verde & *urõ & ura & unõ \\
\hline 14 (s23) & árvore, pau & *ku & ku & $k u$ \\
\hline 15 & aumentativo & $*-t \int i t \int i$ & $-t \int i t f i$ & $-t \int i t f i$ \\
\hline 16 & avó & *kure & kure & kure \\
\hline 17 & avô & *t $\int u t a$ & t futa & hotõ $\tilde{3}^{38}$ \\
\hline
\end{tabular}

33 O elemento dzi representa provavelmente a palavra para 'osso'.

${ }^{34}$ Observe que as várias línguas Tupí têm uma forma similar.

35 Este cognato sugere que a simplificação do ditongo em Djeoromitxí antigo ocorreu antes do funcionamento do alofone do $/ \mathrm{m} /$.

36 Uma explicação muito especulativa para estes cognatos possíveis é que ocorreu omissão do glide final em ambas as línguas, enquanto, além disso, teve metátese das sílabas em Djeoromitxí.

${ }^{37}$ A semelhança com o verbo kerai- 'ir, ir embora, andar' em Kwazá é forte e pode representar uma razão para não reconstruir este item.

38 Esta palavra indubitavelmente contém a mesma raiz etimológica para 'masculino' presente em DJE təru 'esposo' (96) e hut $\int i$ 'pai' (156). Não obstante a pronúncia de hotõ 'avô' e as suas derivações, como hotõkamu 'irmão mais novo do avô', sempre envolver [0] em vez de [u], talvez por causa do /õ/ na sílaba seguinte, assumo que em Djeoromitxí antigo era fonemicamente /u/. 


\begin{tabular}{|c|c|c|c|c|}
\hline 18 & banco, esteira & *nĩpraj & nĩpraj & nĩpe \\
\hline 19 & banhar & $* t \int 0$ & $t \int 0$ & $-r t, h t$ \\
\hline $20(s 49)$ & barriga & *prika & prika & pika \\
\hline 21 & bater (timbó) & *prõ & pro & põ \\
\hline 22 & batoque para o nariz & *nĩkoku & nĩkoku & $n i ̃ k u k u$ \\
\hline $23(s 54)$ & beber & & 0 & nõ \\
\hline 24 & beneficiário & $(* \varepsilon n \tilde{t})$ & กว̃ & $\varepsilon n i$ \\
\hline $25(s 42)$ & boca & *t $\int a k o$ & ţako (nuku) & -raku, hakt \\
\hline 26 (s97) & bom & & hãwi & $m \varepsilon d z \psi$ \\
\hline 27 & braço, galho & *t $\int a p a$ & t〕apa & hapa, rapa \\
\hline $28(s 90)$ & branco & & mãõ & kənũrt \\
\hline 29 & brincar & *hãtõj & hãtəj & hõtõ \\
\hline 30 & brinco & *nĩpikuj & nĩpikuj & nipiku \\
\hline 31 & buchada, bucho grande & *nũt]u & nut $\int u$ & nõru \\
\hline 32 & buraco & $*_{-}-k 0$ & $-k o$ & $-k t$ \\
\hline $33(s 38)$ & cabeça & & kaj & kuãka \\
\hline 34 (s37) & cabelo & & kai & kuãhi, hi \\
\hline 35 & cabelo de trás & *kaw & kaw & kau \\
\hline 36 & cabo & *t & ţoko & $-r u k t$ \\
\hline 37 & cacho de côco de aricuri & *mətajt $\int u$ & mətajt $\int u$ & materu \\
\hline 38 (s21) & cachorro & & kura & wa \\
\hline 39 & cajá & *urənĩ & urənĩ & urenĩ \\
\hline 40 & calango & *mrãjdzi & mrãjtfi & $m \tilde{\varepsilon} d z i$ \\
\hline 41 (s85) & caminho & ${ }^{*} W I$ & $W I$ & wik ${ }^{39}$ \\
\hline 42 & campo & *rehi & retfi & hehi \\
\hline 43 & caniço & *kunĩkurõ & kunĩkuro & kunĩkunõ \\
\hline 44 & cansado & *t八amə & tfamə & -ramə, hamə \\
\hline 45 & canta & *t $\int u a$ & tfua & -ruwa, huwa \\
\hline 46 & capemba, paxiúba & 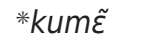 & kum $\tilde{\varepsilon}$ & kume \\
\hline 47 & cará & *mu & $m u$ & $m u$ \\
\hline 48 & cará grande & *mutfitfi & mutfitfi & mutfitfi \\
\hline 49 (s29) & carne & *nĩ & $n \tilde{I}$ & nĩ \\
\hline 50 & caroço de aricuri & *mətaj & mətaj & məte \\
\hline 51 & carrapato & *tfitfika & tfitfika & tfitjika \\
\hline $52(s 27)$ & casca & $* k \partial$ & $k \partial$ & kə \\
\hline & casca, c. de noz, besouro & *kakə & kakə & kakə \\
\hline
\end{tabular}

\footnotetext{
${ }^{39}$ A forma Djeoromitxí pode conter o classificador - $k$ t 'buraco' (32), simbolizando que o caminho está coberto de vegetação.
} 
54 castanha

cesto pequeno

chapéu

cheio

chifre

chorar, cantar, gritar

chover

chupar

chuva

cigarra

cinzas $^{40}$

claro, luz

cobra

cobrir, tampar

colar

comer

comer2

comprido

contar, ensinar

coração

corda, envira

cordão para tanga

corte de cabelo, aba

couro, pele ${ }^{42}$

cru

cupim

curar, rezar

cutia

dar

DAT

deitar

dente

*urə
*pupuka
*kanũ
*mõ
*rõko
*u
*piti
*pitjə (mrə)
*praj
*mrãj
*hetfəj(to)
*m(.)rĩ(to)
*pu
*ku

*pamo

*mə(tutu)ka

*tsukə

*unĩ

*kuro

*kə

* pit

*ire

*wi

*təri

* $\tilde{u}$

*ri

(*..rãj)

*t]o urə

pupuka

kanũ

məj

nĩpakojku

mõ

roko

u

nãj

piti

pikəmrə

praj

mrãj

hekəjto

mrãto

pu

ku

rehãtfi

pamõ

maka

tjukə

unĩ

kuro

kə

$p \dot{t}$

ire

wi

tari

ũ

ri

kõrãj

tjokrihã ${ }^{43}$
urE

pupuka

kanõ

dze(wi)

imeku

$m \psi$

hõkt

$u$

nipa

piti

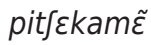

pa

$m \varepsilon$

het $\int \varepsilon$

mĩri

pu

ku

kuritfi

pamt, pawt ${ }^{41}$

mətutuka

-rukə, hukə

unĩ

kurt

kə

pi

ire

wi

teri

õ

ri

ure

$(-) r t$

\footnotetext{
${ }^{40}$ A palavra DJE kamẽ sozinha também significa 'cinzas' e pode conter o elemento classificador -ka 'redondo' (224) e um elemento não transparente que é relacionado etimologicamente com ARI -mrə 'pó'. A palavra ARI significa literalmente 'pó de fogo'.

${ }^{41}$ Existe uma alternância entre $/ \mathrm{m} / \mathrm{e} / \mathrm{W} /$ em Djeoromitxí.

42 Nas línguas Jabutí, trata-se da mesma palavra que (52).

${ }^{43}$ Esta palavra, que foi também freqüentemente pronunciada como [t $\left.\int u k r i h a ̃\right]$, não está completamente analisável. Também a palavra DJE, que mostra similaridade com o verbo ruu 'amolar', não é completamente entendida.
}

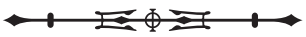




\begin{tabular}{|c|c|c|c|c|}
\hline 86 & derrubar, roçar & *prõ & pro & põ, pũ, kiri \\
\hline 87 & devagar & *hãt.j & hãtãj & hõtoi \\
\hline 88 (s71) & dizer & & tJaroko & piru, rumə \\
\hline 89 & doer, doente, azedo, forte & *t5omi & tكomi & -rumi, humi \\
\hline $90(s 12)$ & dois & & heri & dзzmu \\
\hline $91(s 60)$ & dormir & *nũtõ & nũtõ & nõtõ \\
\hline 92 & em cima & $* t \int u t \int \varepsilon$ & t $u t \int \varepsilon$ & $-r u t \int \varepsilon$ \\
\hline 93 & enfiar, mudar roupa, inserir & $* t \tilde{t}$ & $t \tilde{}$ & $t i ̃$ \\
\hline 94 & escorrega-macaco (árvore) & *hawajte & hawajte & hawate \\
\hline 95 & esposa & *krajdzi & krajtfi & tədzi \\
\hline 96 & esposo & *krajtfu & krajtfu & təru \\
\hline 97 & espremer líquido & *imi & imĩ & imi \\
\hline 98 (s5) & esse & & mwعhã, nihã & mupe, me, nudzu \\
\hline $99(s 4)$ & este & & ãjhã & $w \varepsilon$ \\
\hline 100 & esticar, puxar, ajeitar & *tə(j)təj & tə(j)təj & 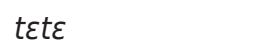 \\
\hline $101(s 74)$ & estrela $^{44}$ & & wirəwirə & bzirebzire \\
\hline $102(s 74 a)$ & estrela grande & & warəwarə & kurawãtsi \\
\hline $103(\mathrm{~s} 1)$ & eu & & ihe, i- & $h *, \varnothing$ \\
\hline 104 & farpas de flecha & *itfopu & itfopu & irtpu \\
\hline $105(\mathrm{~s} 16 \mathrm{a})$ & fêmea, mãe & $* d z i$ & $t \int i$ & $d z i$ \\
\hline 106 & ferver & *toto & toto & tutt \\
\hline $107(s 69)$ & ficar em pé & & 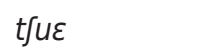 & tumĩ \\
\hline 108 (s53) & fígado & *mə & mə & $m ə$ \\
\hline 109 & filho & *wikoko & wikoko & wiktku \\
\hline 110 & filho, filha, filhote & *kraj & kraj & to \\
\hline 111 & flor & *t awa & tfawa & -rawa, hawa \\
\hline 112 & fluir, derramar, correr, jogar & *kuhi & kui, kut $i^{45}$ & kuhi \\
\hline 113 (s82) & fogo & *pitfə & pikə & pit $\int \varepsilon$ \\
\hline $114(s 25)$ & folha, espinho & *-nĩ & $-n \tilde{i}$ & nĩ \\
\hline 115 & formar, tecer, encostar & *pət $\sqrt{a}$ & pәtكa, рәа & pəra \\
\hline 116 (s94) & frio & & (kə)tfitfi & (dzidzirtu) \\
\hline 117 (s81) & fumaça $^{46}$ & & tfio & 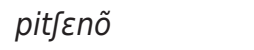 \\
\hline 118 (s45) & garra, unha & *nĩkətaj & nĩkətaj & nikəte \\
\hline 119 & gavião & *pĩjkuri & pə̃jkuri & pikuri \\
\hline
\end{tabular}

\footnotetext{
${ }^{44}$ Esta palavra ocorre em várias línguas da região e pode representar um empréstimo (van der Voort, 2005, p. 386).

${ }^{45}$ A segunda variante ocorre somente sob negação.

${ }^{46}$ A palavra Djeoromitxí é transparente e pode significar literalmente 'pó de fogo', enquanto a palavra Arikapú pode ser relacionada etimologicamente a uma palavra que significa 'cabelinhos'.
}

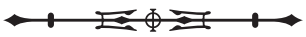


jenipapo

gongo de aricuri

gongo pequeno, tapuru

gordura, banha

grande ${ }^{47}$

guardar, ter, botar, esconder

haste da flecha

homem

inambu (geral)

inambu relógio

ingá

INSTR

INTENS

ir embora

irara, papa-mel

irmã (mais velha)

jabuti

japu, rubixá

jirau, moquém

joelho ${ }^{52}$

jogar, perder, cair, derramar

lábios, cuspe

labrete

barro para potes e louça

lamparina, vela, tocha, breu
*mI

*t $\int a n \tilde{~}$

*uri

*tũ(ka)

*dzi

*məku

$* d z u i^{48}$

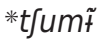

*nว ${ }^{49}$

*wehe

*kũ

*mejmia ${ }^{50}$

*t $\int u h \varepsilon$

*mi.ku

*(a)rimu

*kamekə

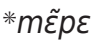

(*k..aj)

*tJokə

*tfatij

*mr(.)

*hãtfo
mI

tfanz̃ka, hanə̃ka

uri

tuka

rukre, tfitfi

tfi

məku

onว̃hย

mikraj

tfui

tรumã

nә

wehe

kũ

mejmia

t $\int u h \varepsilon$

miaku

arimu

kamekə

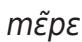

kuraj

tjokə

tfatij

mrõ

hãkə mi

hanõ

uri

tõ

tfitfi

dzi

maku

$t \int t$

mitə

dzui

humĩ, homĩ

ə

wehह

kõ

meibzia

huhe

bzicku

himu

kamekə

pepe

kthi

-rukə, hukə

hati

mã

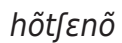

47 Veja (15).

48 Veja nota (17).

${ }^{49}$ Este cognato representaria uma violação do ambiente condicionante da correspondência ə: $\varepsilon$, se não tivesse desaparecimento do *n em Djeoromitxí.

50 Possivelmente, esta palavra estava mais transparente em Proto-Jabutí, com o sentido 'dono do mel'. Em Djeoromitxí, com me 'mel' e bzia 'dono', a palavra ainda está quase transparente, especialmente se consideramos a palavra alternativa mei 'mel' (lit. 'líquido de abelha'), mas os equivalentes em Arikapú viraram homófonos: mio 'mel', 'dono, companheiro'. É também possível que Arikapú mejmia represente um empréstimo do Djeoromitxí.

${ }^{51}$ Este par pode representar um empréstimo do Makurap (família Tuparí) biaku 'jabuti', que faz a impressão de ser reconstruível em Proto-Tuparí (Moore; Galucio, 1994). Como mencionado na nota 22, a forma pode todavia ser emprestada à época do Proto-Jabutí e, conseqüentemente, pode ser reconstruível. A mudança [ja] > [jह] pode ser motivada por uma tendência universal.

52 Nas palavras para 'joelho', que parecem cognatos parciais, podemos supor que o*m convergiu em Djeoromitxí com /p/ sob desnasalização da vogal seguinte, enquanto foi transferido como previsto em Arikapú.

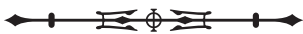




\begin{tabular}{|c|c|c|c|c|}
\hline $145(s 44)$ & língua & 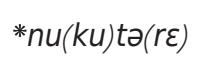 & nukutəre & nũte $(r \varepsilon)^{53}$ \\
\hline 146 & locativo & $*-t \int \varepsilon$ & $-t \int \varepsilon$ & $-t \int \varepsilon$ \\
\hline 147 (s73) & lua & $(\text { *kupa })^{54}$ & kupa & kupa \\
\hline 148 & lugar & *kutfiprajka & kutfiprajka & kutfipaka \\
\hline 149 & macaco prego & *mirə & mirə & bzire \\
\hline 150 & macaco sauim & *mihi & $\operatorname{mit} f i$ & bzihi pikort \\
\hline 151 & macaxeira & *mure & mure & mure \\
\hline 152 & maduro, amadurecer & $* t \int u$ & $t \int u$ & $-r u, h u$ \\
\hline 153 & mandar & *matĩ & matã & matĩ \\
\hline $154(s 48)$ & mão56 & *nĩ.u & nĩkaj, nĩku, niku & nihu, nĩhu \\
\hline 155 & mascar & *pa & pa & pa \\
\hline 156 (s17a) & masculino & $* t \int u, * t \int u t \int i$ & $t \int u, t \int u t \int i$ & $-r u$, hutfi \\
\hline 157 (s62) & matar (à flechada) & & konə & hi, hirokt \\
\hline 158 (s62a) & matar (à pancada) & *t.mr. & tãmrã & tumi \\
\hline 159 & meio & *mə & mə & mə \\
\hline 160 & melada & *kanə & kanə & kane \\
\hline 161 (s96b) & menina $^{57}$ & *nũnika & nunika & nõĩka \\
\hline 162 & mexer, remar, mistura & *kot $\int u$ & kotfu & ktru \\
\hline 163 & moer & *kũ & kũ & kõ \\
\hline $164(s 86)$ & montanha, serra & & kam̃̃ & uri \\
\hline 165 & moquear & *rĩ & $r \tilde{}$ & nĩ \\
\hline $166(s 56)$ & morder & $* k u$ & ku & ku \\
\hline $167(s 61)$ & morrer & & pi & hahi \\
\hline 168 & mosquito, carapanã & *pat $I I$ & pat $\pi \tilde{I}$ & pat $\pi \tilde{I}$ \\
\hline $169(\mathrm{~s} 10)$ & muito & & hekumrã & hõta \\
\hline 170 (s16) & mulher & *paku & 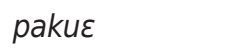 & paku \\
\hline $171(\mathrm{~s} 63)$ & nadar & & (i)pri & iwa \\
\hline $172(s 8)$ & não & *mãj & mãj & mã \\
\hline 173 & não é? & *nĩ & nĩ & nĩ \\
\hline $174(s 41)$ & nariz & & nĩnĩka & nĩktte \\
\hline
\end{tabular}

53 O elemento -re provavelmente representa o classificador 'verme', discutido em Morfossintaxe, que está fossilizado em ARI e opcional em DJE.

${ }^{54}$ As palavras para 'lua' nas línguas da região do Guaporé apresentam semelhanças que podem se originar de difusão areal (van der Voort, 2005). A semelhança da forma kupa das línguas Jabutí à forma de outras línguas (famílias), como por exemplo Mekens e Wayuru (família Tuparí) pakuri 'lua', pode dar razão para não reconstruir este item. Observe também “Mashubi” < pakari kapú> 'lua' (Rivet, 1953).

${ }_{55}$ A palavra pikort, que não foi traduzida, é provavelmente um termo descritivo.

${ }^{56}$ Em Djeoromitxí não se faz uma distinção entre 'mão' e 'dedo', em Arikapú se faz, sim: nĩku 'dedo', nĩkaj 'mão', nĩkajku 'todos dedos da mão'. A forma para 'dedo' pode ser reconstruída em Proto-Jabutí como *nĩku.

${ }^{57}$ Esta palavra é etimologicamente relacionada com (230).

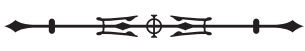




\begin{tabular}{|c|c|c|c|c|}
\hline 175 (s8a) & NEG, não & *tõ & tõ & tõ \\
\hline 176 (s92) & noite & *patfitfu & patfiu & patfiru \\
\hline 177 & NOM & *h. & -hã & hə \\
\hline $178(s 100)$ & nome & *tôhĩ & tatfi & tõhĩ \\
\hline 179 (s3) & nós & *hi.., *hi- & tfihs, $t \int i-$ & hirt, hi- \\
\hline 180 (s96) & novo & *kamu & kamu & kamu \\
\hline 181 (s96a) & novo2 & & & nute (inan) \\
\hline $182(s 80)$ & nuvem & *me(ko) & $m \varepsilon$ & $m \varepsilon(k t(k t))^{5}$ \\
\hline $183(s 40)$ & olho & 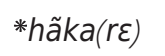 & hãkare & hõka \\
\hline 184 (s39) & orelh $a^{59}$ & (*nĩpi) & nipwaro & nĩpi \\
\hline 185 (s31) & Osso $^{60}$ & $* d z i$ (ou *i) & $t \int i, i$ & $d z i$ \\
\hline 186 & outro, companheiro & *tfanãj & tfanãj & -rəne \\
\hline 187 (s58) & ouvir & *mə & mə & mə \\
\hline 188 (s33) & ovo ${ }^{61}$ & *(.) $\tilde{\varepsilon}$ & $-r \tilde{\varepsilon}$ & $d 3 \varepsilon$ \\
\hline 189 & pamonha, comida & *nũ & nũ & nõ \\
\hline 190 (s20) & pássaro62 & & (ãmitfi) & mitəitfu \\
\hline $191(s 46)$ & pé & *praj & praj & pa, panĩkə \\
\hline 192 (s77) & pedra & *kra & kra & ta \\
\hline 193 & pegar, achar & *paj & paj & $p \varepsilon$ \\
\hline 194 (s19) & peixe & $(* \min \tilde{)})$ & minũ & $\min \tilde{o}^{63}$ \\
\hline 195 & pele da casca, pêlo & *kəmõ & kəmõ & $k ə m \psi$ \\
\hline 196 (s36) & pena & & to & rari \\
\hline 197 & pendurar, amarrar & *tət]əj & təkəj & $t \varepsilon t \int i$ \\
\hline 198 (s15) & pequeno & & mrəj & to \\
\hline 199 & perder-se & *atõ & ata & ətõ \\
\hline 200 & pesar, pesado & *kumĩ & kumã & kumĩ \\
\hline $201(s 50)$ & pescoço & *poko & poko, $(k o p o)^{64}$ & ktpt \\
\hline 202 (s50a) & pescoço2 & & ruwaj & reu \\
\hline
\end{tabular}

\footnotetext{
${ }^{58}$ A diferença entre as formas alternativas em DJE não está entendida nesta fase da pesquisa.

${ }^{59}$ A forma ARI vem provavelmente de uma combinação antigamente produtiva que conteve *nĩpt 'orelha'.

${ }^{60} \mathrm{~A}$ ocorrência ou não do /t $\int /$ nas formas Arikapú se deve à maneira que um possuidor for expresso. A forma $i$ ocorre somente em composições, enquanto a forma $t f i$ ocorre após prefixos pessoais ou em composições. Isso levou Eduardo Ribeiro (c.p.) à idéia de que talvez o /t $/$ / seja um reflexo de um possuidor antigo *j-, e que a proto-forma da palavra é $*_{i}$ 'osso'. Neste caso, o/dz/do cognato Djeoromitxí é o resultado de um automatismo que se deve à tendência universal de formar sílabas do tipo CV.

${ }^{61}$ Não foi possível reconstruir em Proto-Jabutí a consoante deste par de cognatos. A nasalidade da raiz Arikapú -rž 'ovo', 'dançar' pode-se explicar com a consoante nasal em Proto-Jê *ỉrẽ 'ovo', 'danç̧ar' (Ribeiro, c.p.).

${ }^{62}$ As palavras se referem a uma espécie de pássaro espećfica. Somente a palavra Djeoromitxí tem também a conotação de 'pássaro em geral'.

${ }^{63}$ Esta reconstrução possivelmente não vale como comprovante do relacionamento genealógico por causa da similaridade com Kwazá (isolado) manini 'peixe' (van der Voort, 2005).

${ }^{64}$ Esta pronúncia alternativa se deve provavelmente à influência de Djeoromitxí, onde deve ter ocorrido metátese de sílabas.
}

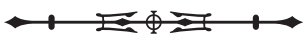




\begin{tabular}{|c|c|c|c|c|}
\hline 203 (s18) & pessoa & & & hikəmt \\
\hline 204 (s22) & piolho & & tao & tõdzع \\
\hline 205 & poço & *kawiru & kawiru & kawiru \\
\hline 206 & ponte & *mirukurõ & mikuro & bzirukunõ \\
\hline 207 & ponto & *nĩnũ & nĩnũ & nĩnõ \\
\hline 208 & porto & *mitfakə & mitjakə & bzirakə \\
\hline 209 & pote, panela, vasilha & *wa & wa & wa, watĩ \\
\hline 210 & pouco & *kokə & kokə & $k \sharp k \partial$ \\
\hline 211 (s91) & preto & & kario & miru \\
\hline 212 & pulmão & *mə(ki)rı & məkrı & məhiri \\
\hline 213 & pupunheira & *ont & oñ̃ & แnĩ \\
\hline 214 & pus & $* t \int u$ & $t \int u$ & $-r u$ \\
\hline $215(s 7)$ & que & & hẼwhã & hatfime \\
\hline $216(s 84)$ & queimar & $* t \int \partial(.)$. & kənə & $t \int \varepsilon t u$ \\
\hline $217(s 6)$ & quem & & & \\
\hline $218(s 93)$ & quente & *tfə & kə & $t \int \varepsilon$ \\
\hline 219 & querer & *iro & iro & $i r t$ \\
\hline 220 (s35) & rabo & & nĩtəj & $u$ \\
\hline $221(s 26)$ & raiz & & niri & rari \\
\hline 222 & rapé, tabaco, cigarro & *padzi & patfi, pai & padzi65 \\
\hline 223 & recipiente, capemba, bolsa & *təkə & təkə & tekə \\
\hline 224 (s98) & redondo & *ka & ka & ka \\
\hline 225 (s59) & saber $^{66}$ & *mə & mə & mə \\
\hline 226 & salgar & $* n \dot{r}$ & $n \dot{t}$ & $i$ \\
\hline 227 (s30) & sangue & & t 0 & kəi \\
\hline 228 & sapo & $(* . k a)^{67}$ & uka & $u k a$ \\
\hline 229 (s99) & seco & *karo & karo & kurt \\
\hline 230 (s51) & seios, peito & *nuni & nunit & nowi68 \\
\hline 231 (s24) & semente, caroço & *hã & hã & hõ \\
\hline $232(s 68)$ & sentar & & nõ & hunã \\
\hline 233 & sobrinha & *prõ & pra & põ \\
\hline 234 (s72) & sol & *tõhã & təhã & tõhõ \\
\hline
\end{tabular}

65 Também pronunciado como [pa'zi].

${ }^{66}$ Esta palavra é homófona com (187) 'ouvir', e provavelmente trata-se da mesma palavra. Além disso, esta palavra é homófona com (108) 'fígado', que é uma palavra diferente. Estas homofonias representam um traço característico das línguas Jê (Ribeiro; van der Voort, no prelo).

${ }^{67}$ Veja (140) e notas 16 e 23.

${ }^{68}$ A pronúncia desta palavra e das suas derivações quase sempre envolve [0] em vez de [u], talvez por causa do glide seguinte. Porém, a pronúncia com [ũ] foi registrada uma vez.

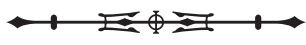




\begin{tabular}{|c|c|c|c|c|}
\hline 235 & taioba ${ }^{69}$ & $* m(). r \tilde{\varepsilon}$ & $m r \tilde{\varepsilon}$ & mire \\
\hline 236 & tamanduá & $\left(\text { * pat } \int u r i\right)^{70}$ & patfuri & paruri \\
\hline 237 & tatu $^{71}$ & *tõw & taw & tõu, tãu \\
\hline 238 & teiú, teju, tejuaçu & *tfaurə & tfaurə & haure \\
\hline 239 & temer & $* p \dot{t}$ & $p \dot{t}$ & pi \\
\hline 240 (s79) & terra & *mĩ(ka) & mĩ(ka) & mĩ(ka) \\
\hline 241 & terreiro & *miku & miku & miku \\
\hline 242 & testículos ${ }^{72}$ & *nũ(.) $\tilde{k} k a$ & nũrẽka & nõdzcká \\
\hline 243 & tia & *dzikũ(ro) & tfikuro & dzikõ \\
\hline 244 & timbó & *tanãj & tanãj & $\tan \tilde{\varepsilon}$ \\
\hline 245 & tirar, pegar & *hĩj & hə̃j & $h \tilde{\imath}$ \\
\hline 246 & toco & *prajka & prajka & paka \\
\hline 247 (s9) & todo ('acabou') & (*..tã) & hətã & bzitã \\
\hline 248 & trazer, levar, ter, ser, vestir & *tə & to & $t \varepsilon$ \\
\hline 249 & tucum, corda de tucum & *nũrõ & nũrõ & nõnõ \\
\hline 250 (s11) & um & & tə̃jw & uitfi \\
\hline 251 & umbaúba & *tõwkuri & tawku & tõkuri \\
\hline 252 & urtiga & *nõ & กว̃ & nõ \\
\hline 253 & urubu & *tõtõt $f i$ & totot $\int i$ & tõtõtfi \\
\hline 254 & urucum & *kutfamrəj & kuamrəj & kurami \\
\hline 255 & vasilha & *maro & məro & mərt \\
\hline 256 & veado & *kurij & kurij & kuni \\
\hline 257 & velho & *rõjtfi & rəjtfi & nõtsi \\
\hline 258 (s57) & ver & *arã & arã & әпо̃ \\
\hline 259 (s88) & verde & *kapi & kapi & kapi \\
\hline 260 & verme, gongo & 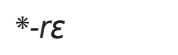 & $-r \varepsilon$ & $-r \varepsilon$ \\
\hline $261(\mathrm{~s} 87)$ & vermelho & *nũr(ã)o & nũrə̃o & nõrt \\
\hline 262 (s66) & vir (chegar) & *prəj & prəj'3 & $p \varepsilon$ \\
\hline 263 (s64) & voar & & tjopo & irariku \\
\hline
\end{tabular}

${ }^{69}$ Ou ocorreu inserção de vogal em Djeoromitxí, ou ocorreu elisão em Arikapú.

70 Esta raiz é cognata em línguas Macro-Jê, como Karajá. Uma vez que existem formas similares em línguas Carib, o seu valor não é muito grande aqui.

${ }^{71}$ Embora esta palavra pareça com formas similares em línguas Tupí, ela parece também com palavras em línguas Jê (Ribeiro; van der Voort, no prelo).

72 Obviamente, esta palavra contém as palavras para 'ovo' e 'redondo', mas a origem da primeira sílaba não é conhecida.

${ }^{73}$ Existe uma outra palavra com um sentido mais específico, pə- 'chegar voltando à própria casa ou aldeia'. Este sentido específico não parece existir em DJE p $\varepsilon$ - (a expressão indicada seria dzcki- 'chegar na própria casa ou aldeia'). Mas, mesmo se pə:p $\varepsilon$ fossem cognatos, isso não necessariamente violaria o ambiente condicional da correspondência ə: $\varepsilon$ (veja As vogais), porque o par contrastivo pə:pə ocorre somente em sílabas átonas.

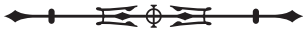


264 (s2)

265 você (SG/PL)

voltar $^{74}$ *a

*m(.) $r \tilde{\varepsilon} h \tilde{\varepsilon}$ ahe, a-

$m r \varepsilon \tilde{\varepsilon} \tilde{\varepsilon}$ adze, a-

mirche

\section{ABREVIATURAS}

\begin{tabular}{|c|c|c|c|}
\hline ABL & ablativo & MAK & Makuráp \\
\hline ARI & Arikapú & $N$ & substantivo \\
\hline c.p. & comunicação pessoal & NEG & negativo \\
\hline COMIT & comitativo & NOM & nominalizador \\
\hline DAT & dativo & PL & plural \\
\hline $\mathrm{DECL}$ & declarativo & SG & singular \\
\hline DJE & Djeoromitxí & 1PL & 1a pessoa plural \\
\hline FUT & futuro & 1s & 1a pessoa sujeito \\
\hline IMPESS & impessoal & $1 \mathrm{sG}$ & 1a pessoa singular \\
\hline INSTR & instrumental & 2 & $2 \underline{a}$ pessoa \\
\hline INTENS & intensificador & $2 s$ & $2^{a}$ pessoa sujeito \\
\hline INTERR & interrogativo & 3 & 3a pessoa \\
\hline
\end{tabular}

${ }^{74}$ Ou ocorreu inserção de vogal em Djeoromitxí, ou ocorreu elisão em Arikapú.

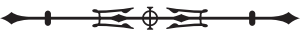

